\title{
Investigation of the Downwelling LW Differences Between the Niamey AMF Main and Supplementary Sites
}

C.N. Long/Pacific Northwest National Laboratory, Richland, WA

P. Gotseff/National Renewable Energy Laboratory, Golden, CO

E.G. Dutton/National Oceanic and Atmospheric Administration, Boulder, CO

April 2008

Work supported by the U.S. Department of Energy,

Office of Science, Office of Biological and Environmental Research 


\section{DISCLAIMER}

This report was prepared as an account of work sponsored by the U.S. Government. Neither the United States nor any agency thereof, nor any of their employees, makes any warranty, express or implied, or assumes any legal liability or responsibility for the accuracy, completeness, or usefulness of any information, apparatus, product, or process disclosed, or represents that its use would not infringe privately owned rights. Reference herein to any specific commercial product, process, or service by trade name, trademark, manufacturer, or otherwise, does not necessarily constitute or imply its endorsement, recommendation, or favoring by the U.S. Government or any agency thereof. The views and opinions of authors expressed herein do not necessarily state or reflect those of the U.S. Government or any agency thereof. 


\section{Executive Summary}

The overall average downwelling longwave (LW) measured at the Niamey supplementary facility (S1) is 6-8 $\mathrm{Wm}^{-2}$ less than that measured by the two instruments located at the ARM Mobile Facility (AMF) main (N1) site. Examination of all other data available at both sites does not reveal any overarching differences that suggest this should be the case. However, examination of the pyrgeometer case and dome temperatures do suggest that the S1 values are also anomalously low, which in turn would explain the downwelling LW anomaly since the LW is calculated using these temperatures. Our recommendation then is to normalize the S1 data to the average N1 value by applying an adjustment factor to the S1 downwelling pyrgeometer case and dome temperatures (in Kelvin), then recalculating the downwelling LW values. The adjustment factor (0.00305) has been determined as that factor that brings the overall average S1 LWdn to agree with the overall average of the two N1 LWdn data series. We note that there is no reason to expect that the two site averages would actually be exactly equal to one another, and thus our recommendation is viewed as likely moving the S1 data in the right direction and by normalizing to the N1 average will help facilitate more meaningful temporal variability studies at least.

It is also strongly recommended that for all future AMF deployments where supplementary sites will also be deployed, that the supplementary instrument systems (complete) be assembled as they will be operated in the field and run for at least a few days beside the corresponding AMF main site instruments, both at the beginning and end of the AMF field campaign. This is absolutely crucial so that all the measurements can be compared pre- and post-experiment to properly relate these measurements and systems, and to detect measurement anomalies such as those discussed in this report. 


\section{Contents}

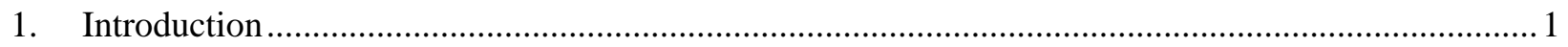

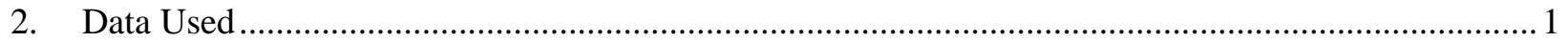

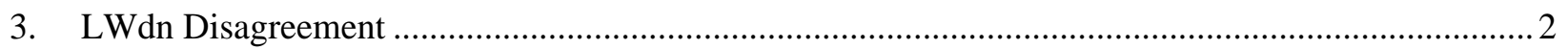

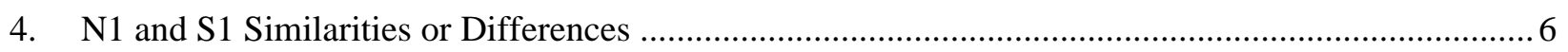

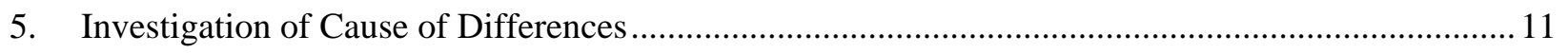

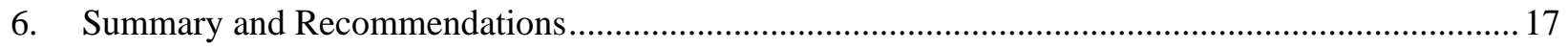

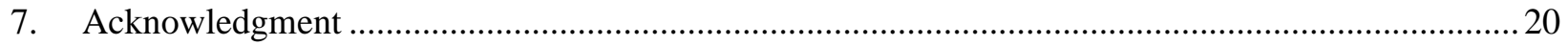

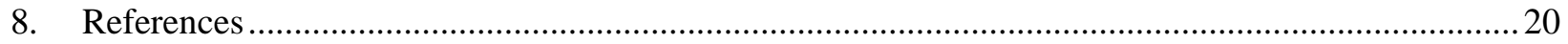

\section{Figures}

1. Time series of LWdn for AMF two main site radiometers and the S1 instrument............................ 1

2. Comparison of \#2 Niamey AMF main and supplementary downwelling LW to the main site \#1

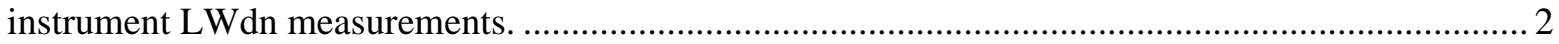

3. Aggregate average\#1 and \#2 Niamey AMF main and supplementary LWdn for the study period...... 3

4. Relative frequency of occurrence for the \#1 and \#2 Niamey AMF main and supplementary LWdn

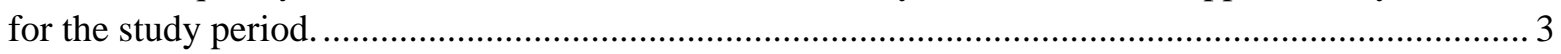

5. Similar to Figure 2, but for LWdn instrument case temperatures.................................................... 4

6. Same as Figure 4, but for LWdn instrument dome temperatures. ..................................................... 5

7. Time series of downwelling global SW for S1 and N1 on 20061206..........................................5

8. Time series of Ta, Tc, and Td for S1 and N1 instruments on 20061206....................................... 6

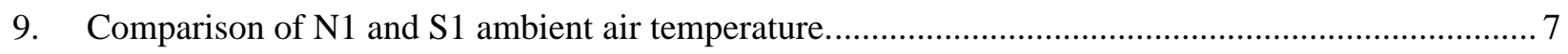

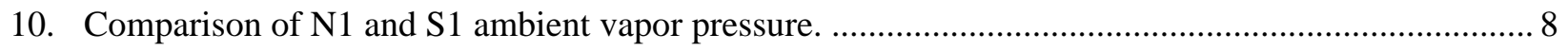

11. Comparison of N1 and S1 estimated clear-sky LWdn................................................................. 8

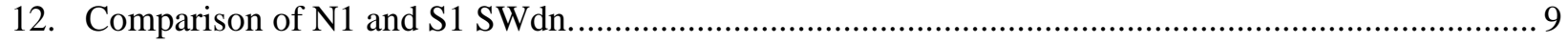

13. Relative frequency of occurrence for the N1 and S1 SWdn for the study period............................. 10

14. Relative frequency of occurrence for the $\mathrm{N} 1$ and S1 $500 \mathrm{~nm}$ aerosol optical thickness.................... 10

15. Comparison of N1 and S1 LWdn separated between day and night. ............................................. 11

16. Aggregate average and standard deviations of the case, dome, and air temperature measurements for the N1 and S1 sites. 
17. Comparison of PIR case and dome minus corresponding air temperatures for the N1 and S1 sites.

18. Comparison of PIR case minus dome temperature difference versus corresponding air temperatures for the N1 \#1 and \#2 and S1 sites.

19. Same as Figure 18, but with the nighttime only S1 data added................................................... 14

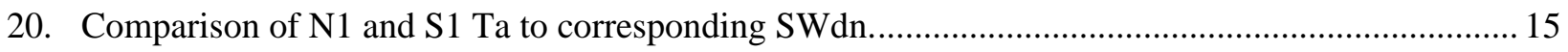

21. Comparison of N1 \#1, \#2 and S1 Td to corresponding SWdn. .................................................... 15

22. Td-Ta difference and Tc-Td difference versus SWdn for the $\mathrm{N} 1$ site. .............................................. 16

23. Same as Figure 19, but for the $\mathrm{S} 1$ site.

24. Picture of the N1 site radiometer and met instruments. Red circle is the ambient air temperature and moisture aspirated enclosure, blue circle is the downwelling radiometers.

25. Picture of the S1 site radiometer and met instruments. Red circle is the ambient air temperature and moisture sun-shielded enclosure, blue circle is the downwelling radiometers.

26. Comparison of 15-minute average of LWdn from 1-minute LWdn data versus LWdn calculated from 15-minute average case and dome temperatures for the N1 PIR\#1 instrument.

27. Comparison on original and “adjusted” S1 LWdn with the N1 PIR\#1 LWdn.

\section{Tables}

1. N1 and S1 aggregate averages and standard deviations of MFRSR spectral aerosol optical thickness and Angstrom coefficient. 


\section{Introduction}

There have been questions regarding the difference in downwelling longwave (LWdn) measurements between the main (N1) and supplementary (S1) sites for the Niamey AMF deployment. Specifically, the S1 LWdn is in the aggregate about 6-8 $\mathrm{Wm}^{-2}$ less than that for the N1 data. Given the 75-km separation of the two sites, while one would expect shorter-term differences, this large a difference in LWdn seems anomalous unless there are fundamental differences in atmospheric state or cloudiness between the two sites. The purpose of the effort reported here is to investigate whether the LWdn difference is "real" or an instrument problem and, if the latter, whether an adjustment can be applied reasonably to the data.

\section{Data Used}

For the analysis results presented here, 15-minute averages of all data have been used to minimize any small timing offsets between the various data systems and between the two sites. The purpose is to directly compare various measurements between the two sites. As such, only those times when all variables being compared have 15 1-minute data available for producing the 15-minute averages are used. In this way, differences due to one site having missing data are avoided. Also, at the start of the deployment, there is an obvious problem in the S1 downwelling LW, as shown in the time series plot of LWdn shown in Figure 1. Identifying the problem for the beginning of the S1 LWdn series or whether it is recoverable has not been investigated here. Rather, the start of the data for these analyses begins on 20060113 at 0900 UTC, and ends on 20061208 at 0600 UTC, with a total of 31,416 15-minute averages.

Time Series LWdn

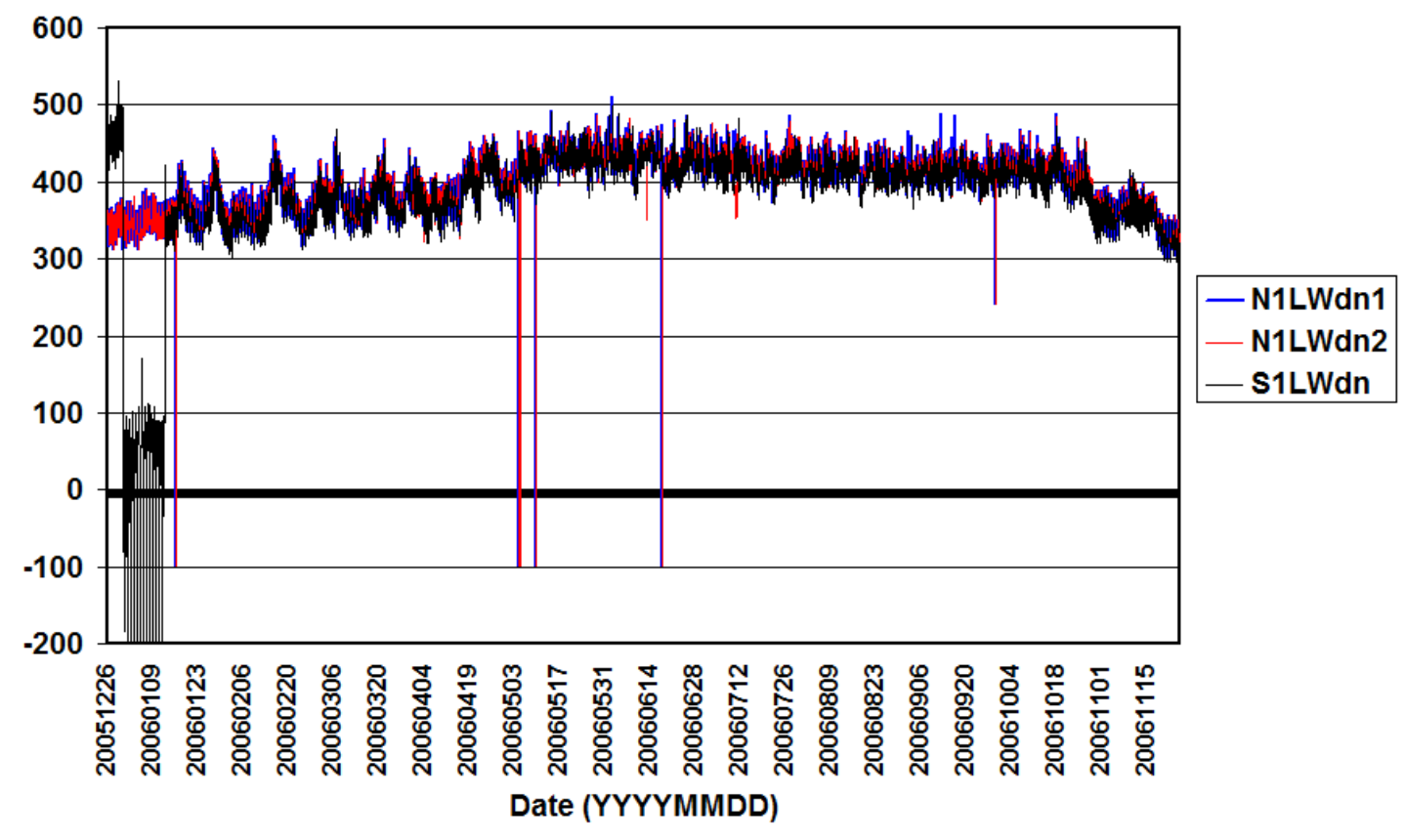

Figure 1. Time series of LWdn for AMF two main site radiometers (blue and red) and the S1 instrument (black). 


\section{LWdn Disagreement}

Fortunately, there are redundant LWdn measurements for the AMF main site. Figure 2 shows a comparison of the \#2 N1 LWdn and the S1 LWdn to the N1 \#1 LWdn data. As is shown, the two N1 instruments agree well, but the S1 data exhibit a lower offset from both the \#1 and \#2 instrument N1 data. Thus there is evidence that the N1 measurements are reasonably "good", and that it is the S1 data that differ. Figure 3 shows the total average LWdn for the three radiometers, where in the aggregate the S1 LWdn at $391 \mathrm{Wm}^{-2}$ is about 7-8 $\mathrm{Wm}^{-2}$ less than the averages for the \#1 and \#2 N1 instruments (399 $\mathrm{Wm}^{-2}$ and $398 \mathrm{Wm}^{-2}$, respectively). Figure 4 shows the relative frequency of occurrence for the three radiometers. Here all three measurement sets exhibit about the same pattern of relative frequency, with the S1 data shifted toward lower values.

\section{Downwelling LW Comparison}

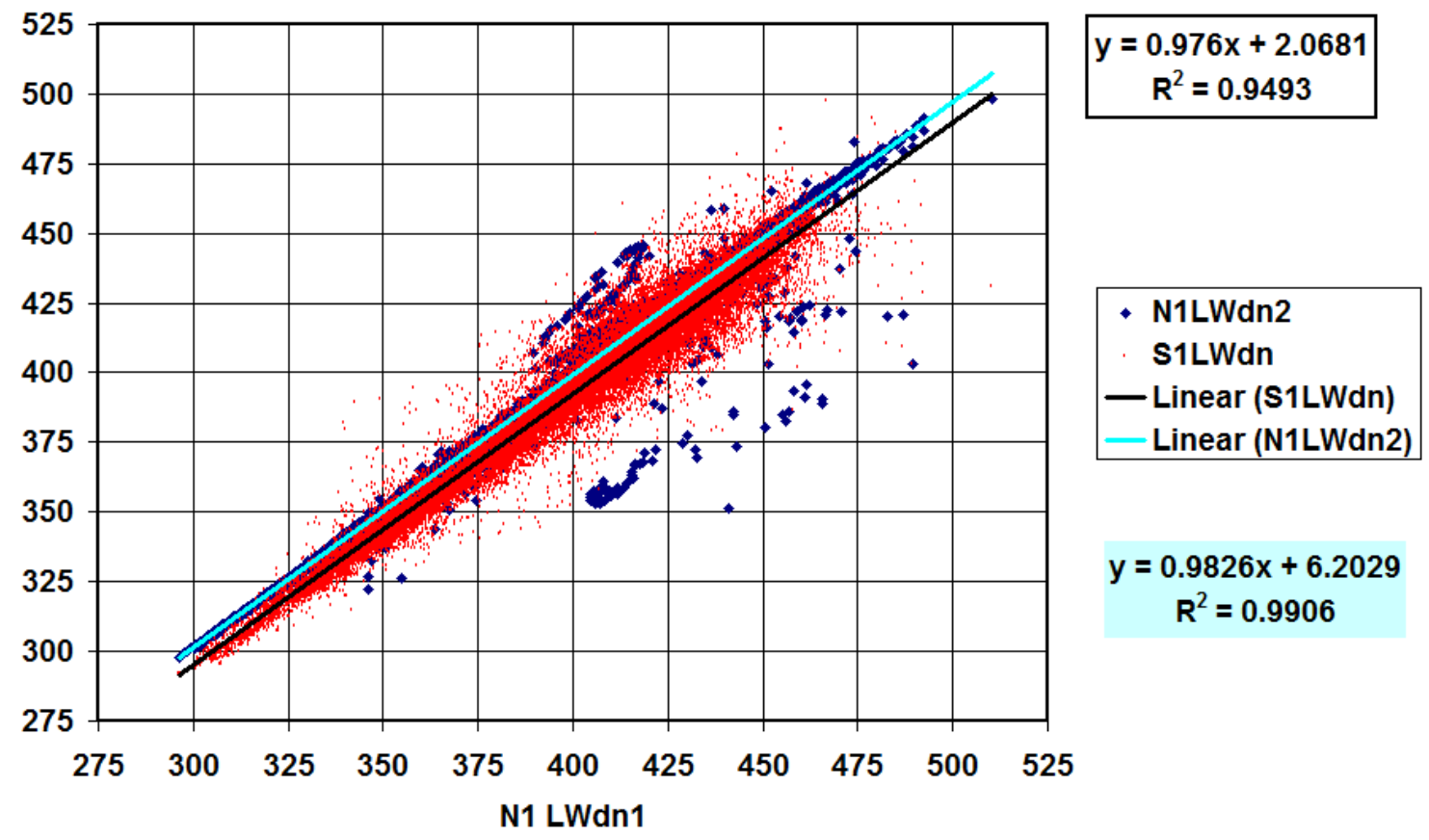

Figure 2. Comparison of \#2 Niamey AMF main (N1) and supplementary (S1) downwelling LW to the main site \#1 instrument LWdn measurements. 


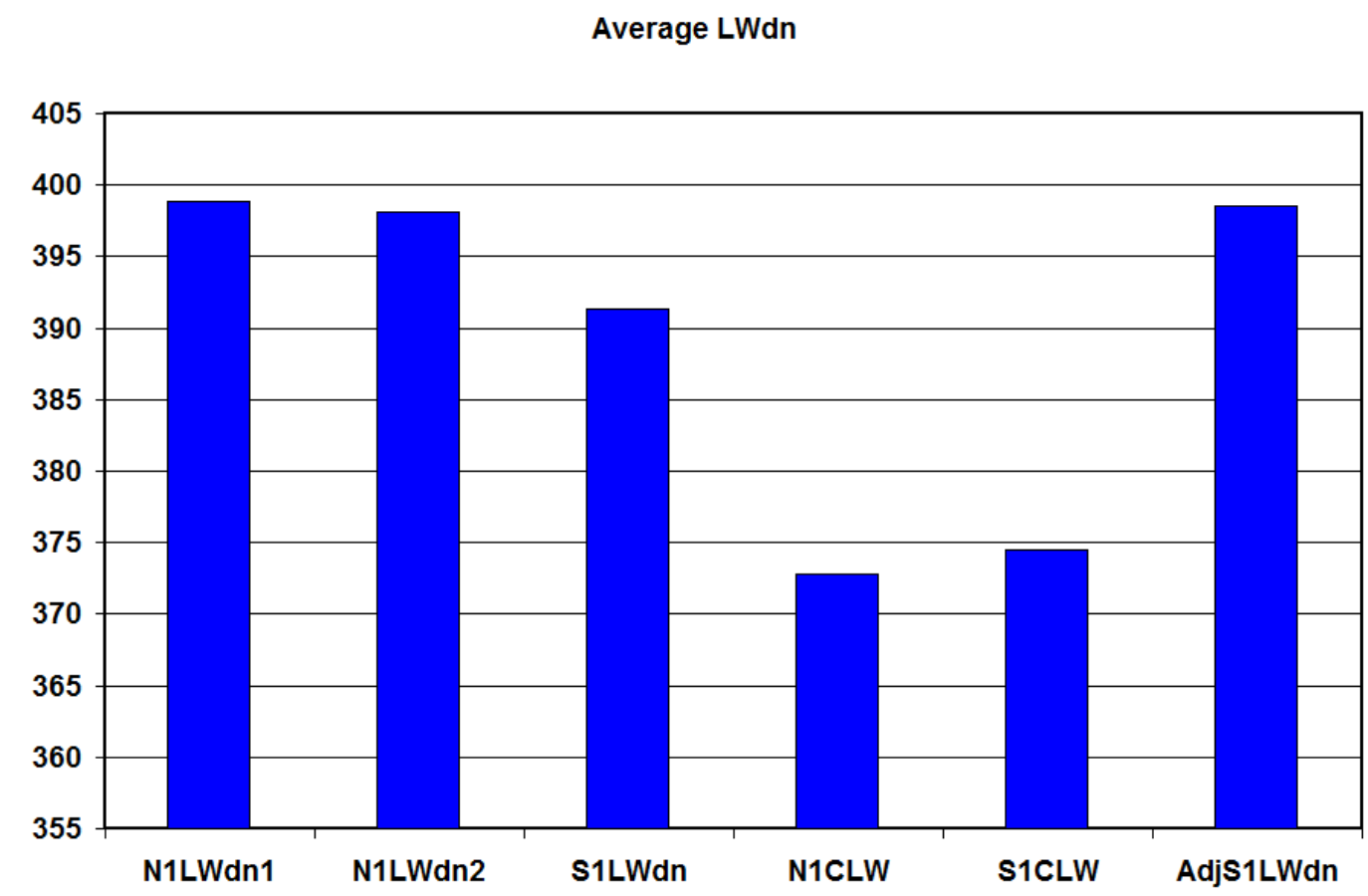

Figure 3. Aggregate average\#1 and \#2 Niamey AMF main (N1) and supplementary (S1) LWdn for the study period. Also shown are the N1 and S1 Brutsaert estimated clear-sky LWdn, and the final adjusted S1 LWdn.

\section{LWdn Frequency Comparson}

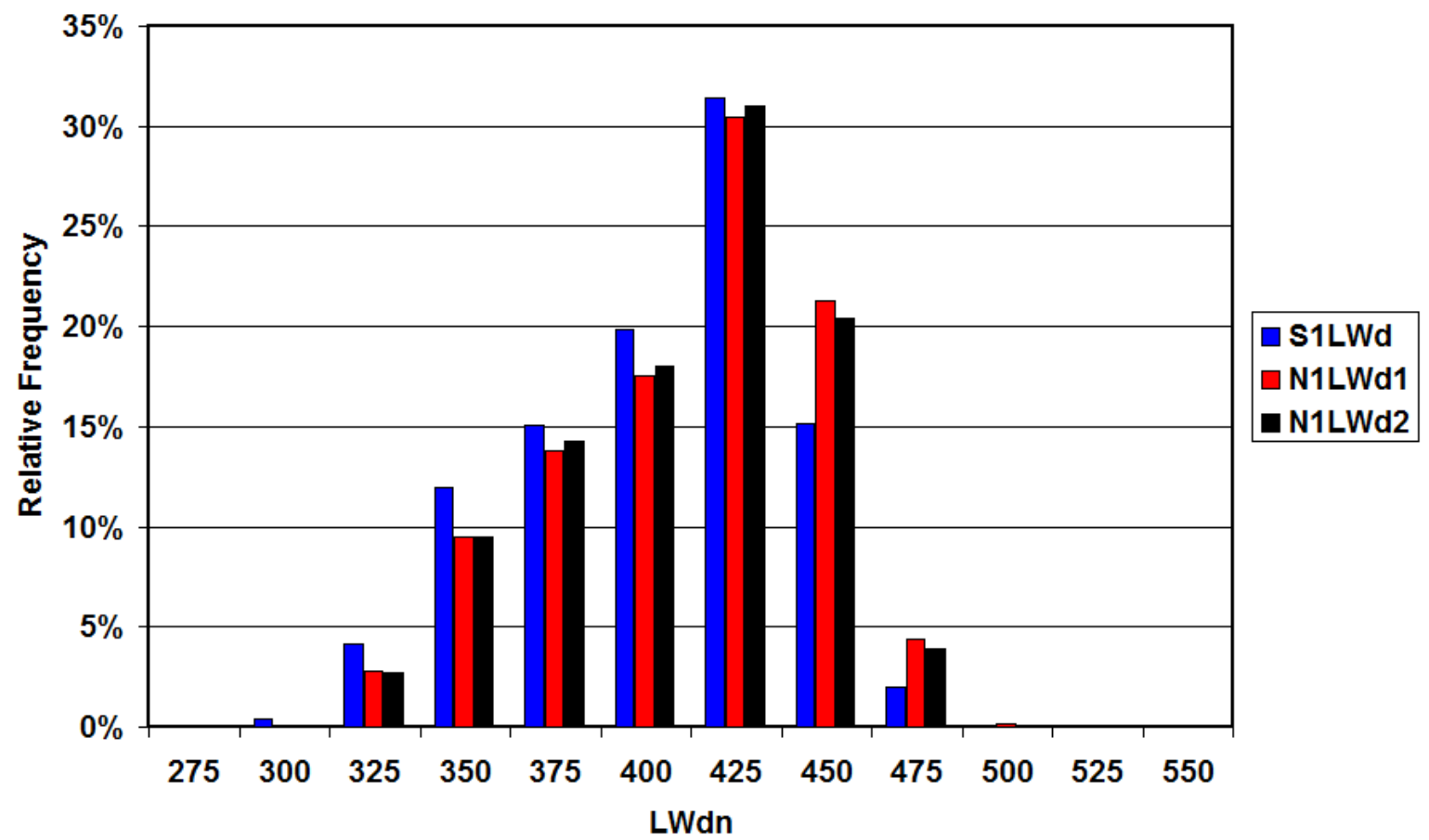

Figure 4. Relative frequency of occurrence for the \#1 and \#2 Niamey AMF main (N1) and supplementary (S1) LWdn for the study period. 
The LWdn measurement includes components of the instrument case and dome temperatures in the calculation. Figure 5 shows a comparison of the three instruments case temperatures (Tc), again using the $\mathrm{N} 1$ \#1 instrument as the reference. As this plot shows, there is good aggregate agreement with the N1 \#2 instrument, but an apparent multiplicative offset with the S1 instrument. The same result is exhibited for the three instruments dome temperature (Td) comparison shown in Figure 6. These differences in case and dome temperatures explain the differences in LWdn between the two sites shown in Figures 2-4, yet the question remains as to whether these differences are real or a measurement problem. One telling clue is shown in Figures 7 and 8. Figure 7 shows the downwelling unshaded pyranometer measurements (i.e., global shortwave) for December 6, 2006. As the plot shows, this day was fairly cloud-free (smoothly varying SW time series) at both sites. Figure 8 shows the corresponding ambient air temperature (Ta), and Tc and Td for the two sites. The daylight Tc and Td for both sites are greater than the corresponding Ta measurements. However, while the nighttime N1Tc and Td are greater than the N1 Ta, the S1 Tc and Td both fall below the corresponding Ta values. The Tc and Td would normally be expected to be somewhat greater than Ta since the fans used in the ventilators do generate some degree of heat, and the detector thermopile energy itself is passed to the case through the cold junction in order to generate the millivolt current. So, at best, these three temperatures (Tc, Td, Ta) should be equal, within the uncertainties (about $0.5^{\circ} \mathrm{C}$ ) of the measurements. There is no physical reason for the case and dome temperatures to be less than the temperature of the ambient air being passed through the ventilator. Thus, this plot serves as a compelling indication that the S1 Tc and Td values are anomalously low.

Case Temperature Comparison

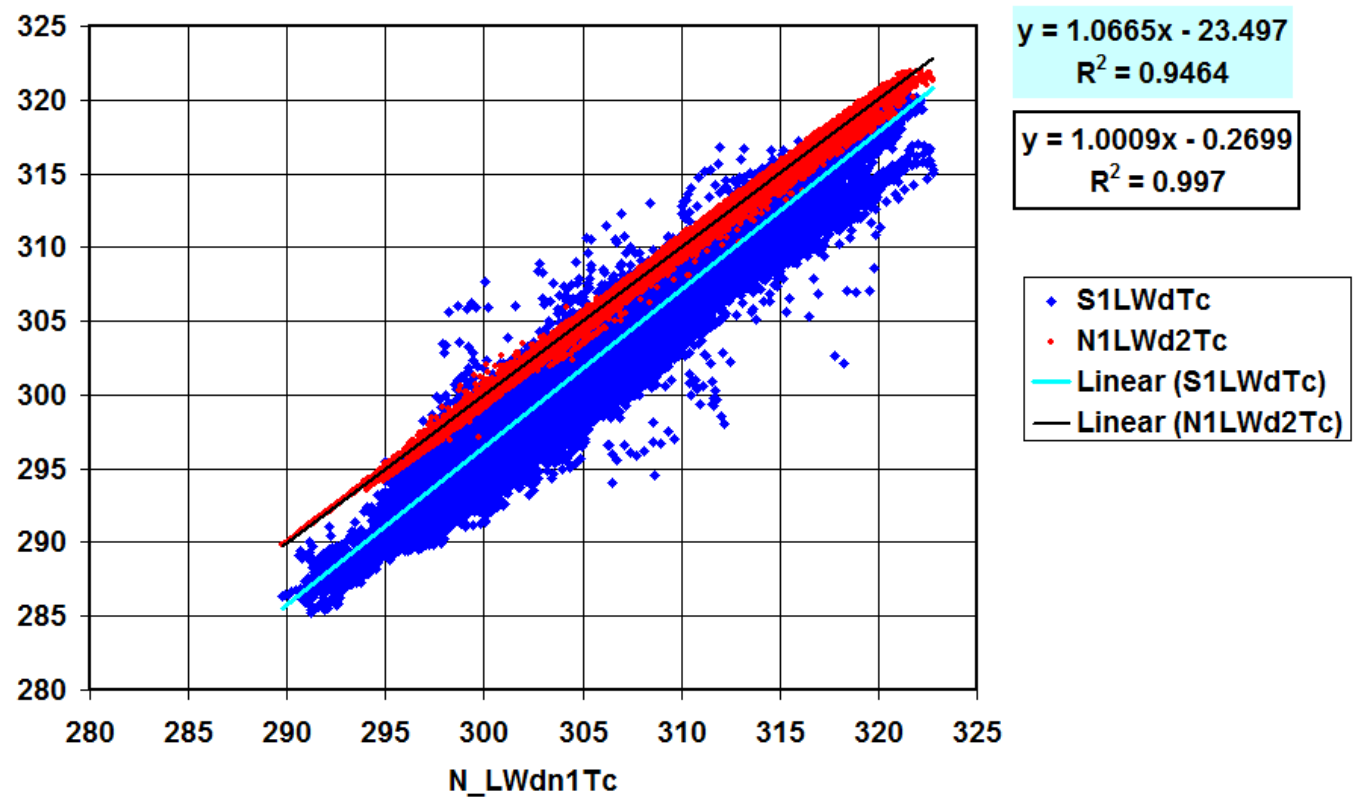

Figure 5. Similar to Figure 2, but for LWdn instrument case temperatures. 
Dome Temperature Comparison

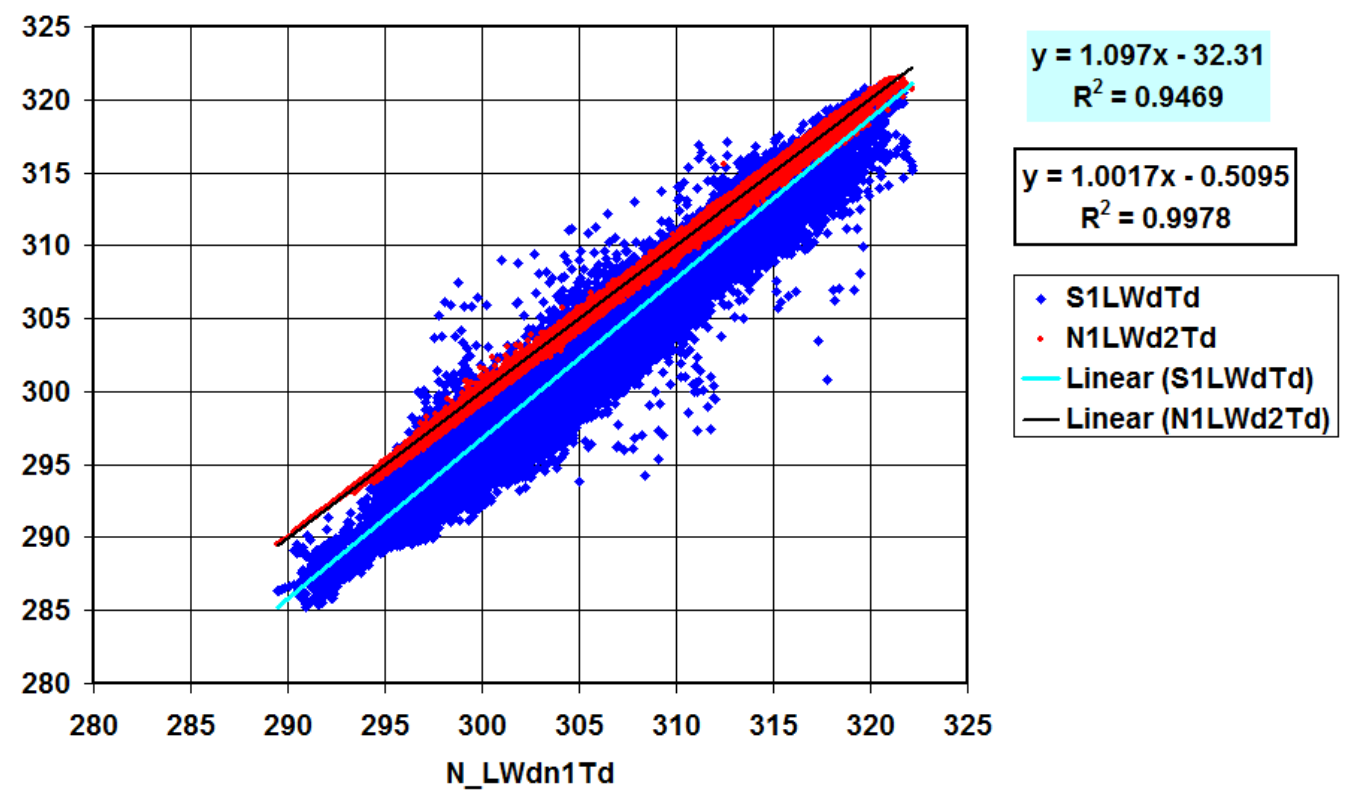

Figure 6. Same as Figure 4, but for LWdn instrument dome temperatures.

\section{N1 and S1 Downwelling Global SW}

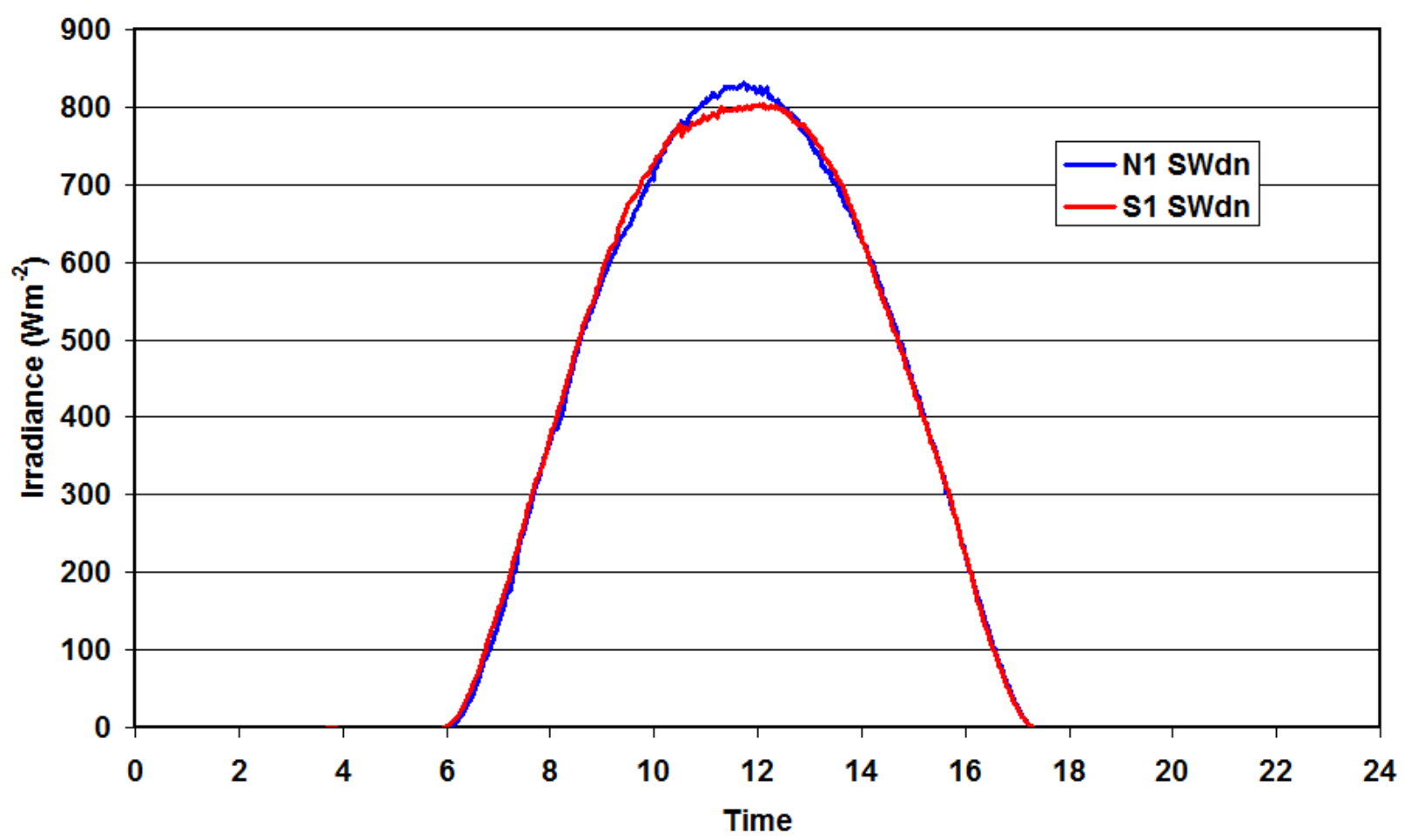

Figure 7. Time series of downwelling global SW for S1 and N1 on 20061206. 
20061206 N1 and S1 Temperatures

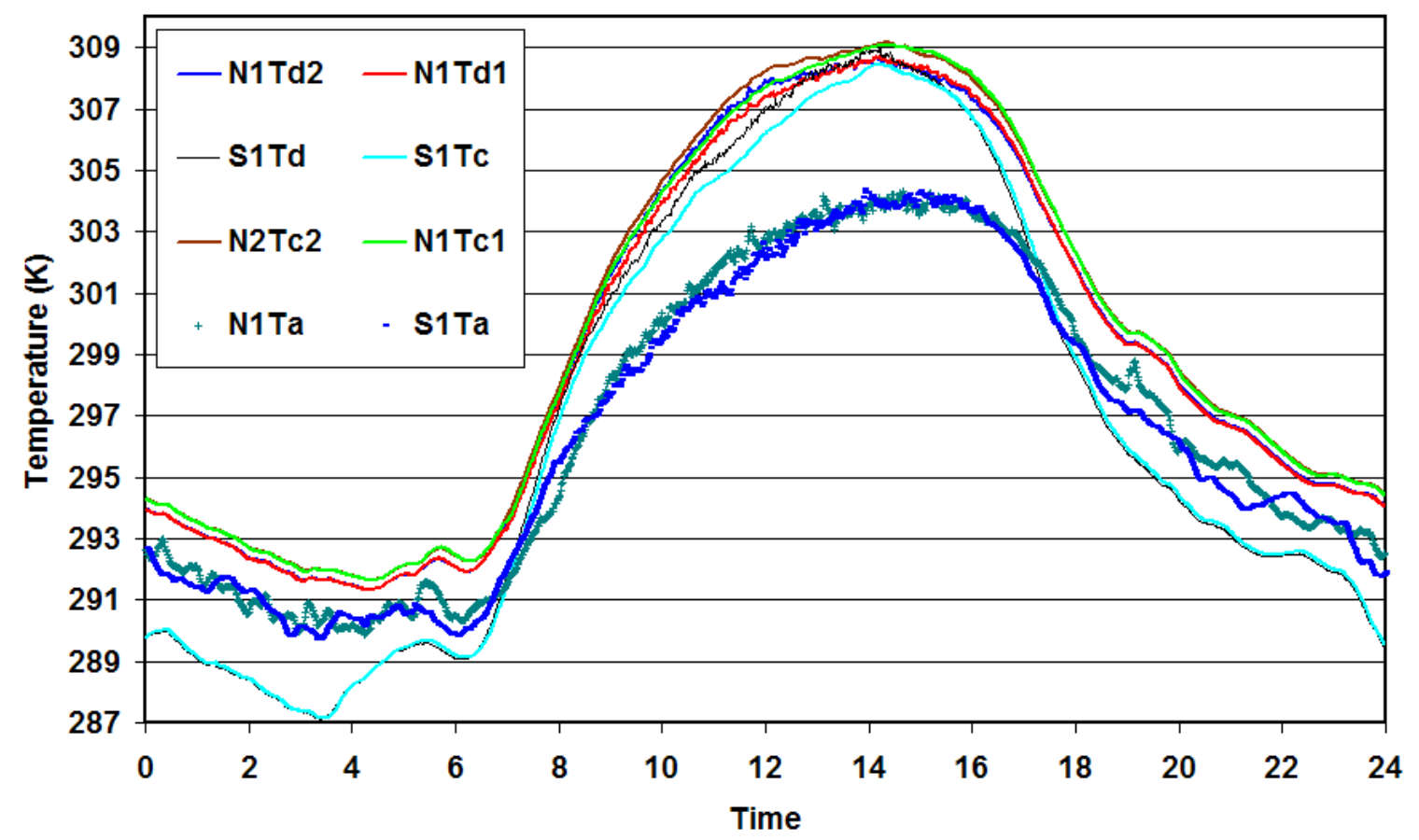

Figure 8. Time series of Ta, Tc, and Td for S1 and N1 instruments on 20061206.

\section{N1 and S1 Similarities or Differences}

If the LWdn difference between the two sites is real, then there also must be differences in the factors that affect the surface downwelling LW. These factors are primarily clear-sky, as a result of atmospheric state, or cloudiness. Unfortunately, while the main site had a sophisticated suite of ARM instrumentation, the S1 site did not. Thus, the means available to investigate differences are limited by the measurements available at the S1 site. The S1 site had a standard suite of surface met instruments (air temperature, RH, vapor pressure, surface pressure, wind speed and direction) as well as the surface radiation system. Figures 9 and 10 show comparisons of the N1 and S1 surface air temperature (Ta), and vapor pressure (Vprs) measurements, respectively. As can be seen, there does not appear to be any significant aggregate differences in these quantities between the two sites. The Ta averages are $30.2^{\circ} \mathrm{C}$ and $30.0^{\circ} \mathrm{C}$, with corresponding standard deviations of $5.2^{\circ} \mathrm{C}$ and $5.3^{\circ} \mathrm{C}$ for the $\mathrm{N} 1$ and $\mathrm{S} 1$ data, respectively. The Vprs averages are $1.45 \mathrm{kPa}$ and $1.52 \mathrm{kPa}$, with corresponding standard deviations of $0.93 \mathrm{kPa}$ and $0.98 \mathrm{kPa}$ for the N1 and S1 data, respectively.

To further test the significance with respect to the LWdn of the small Ta and Vprs differences shown, we calculate and compare estimated clear-sky LWdn between the two sites. As noted by Ohmura (2001), under clear (i.e., cloudless) skies typically about 2/3 of the measured downwelling LW at the surface comes from the first $100 \mathrm{~m}$ of atmosphere above the instrument, with about $90 \%$ of the signal coming from the lowest $1 \mathrm{~km}$ of the atmosphere. This occurs because the warmest and highest concentration of greenhouse gases resides near the surface, with water vapor amounts being the most variable of the greenhouse gases. Brutsaert (1975) developed a formulation based on Schwarzschild's equation of radiative transfer for estimating the clear-sky downwelling LW using only inputs of measured screen 
height (2 m) surface air temperature and moisture amount. He then used an analysis of the U.S. standard atmosphere to determine the needed "lapse rate coefficient” with a value of 1.24. Thus, the original Brutsaert formulation is:

$$
\begin{aligned}
& \varepsilon_{\mathrm{c}} \approx \mathrm{C} *\left(\mathrm{e} / \mathrm{T}_{\mathrm{a}}\right)^{1 / 7} \\
& \mathrm{LW}_{\mathrm{c}} \approx \varepsilon_{\mathrm{c}} * \sigma * \mathrm{~T}_{\mathrm{a}}{ }^{4}
\end{aligned}
$$

Where $\mathbf{T}_{\mathbf{a}}$ is the ambient air temperature in $\mathrm{K}$, $\mathbf{e}$ is the vapor pressure in $\mathrm{mb}, \mathbf{C}$ is the effective temperature/humidity lapse rate coefficient (1.24 for the US standard atmosphere), $\boldsymbol{\sigma}$ is the StephanBoltzman constant, $\boldsymbol{\varepsilon}_{\mathbf{c}}$ is the effective clear-sky broadband emissivity, and $\mathbf{L} \mathbf{W}_{\mathbf{c}}$ is the estimated downwelling clear-sky LW.

Figure 11 shows a comparison of the estimated clear-sky LWdn calculated using the Brutsaert equations between the two sites with the respective air temperature and vapor pressure measurements (compared in Figures 9 and 10). This plot shows no significant differences in the aggregate clear-sky downwelling LW comparison. As shown in Figure 2, the total average clear-sky LWdn between the two sites is within 1.7 $\mathrm{Wm}^{-2}$ of each other, with values of $372.8 \mathrm{Wm}^{-2}$ and $374.5 \mathrm{Wm}^{-2}$ for the $\mathrm{N} 1$ and $\mathrm{S} 1$ sites, respectively. These results suggest that to first order there are no significant atmospheric state differences between the two sites that would cause the S1 LWdn to be in the aggregate 7-8 $\mathrm{Wm}^{-2}$ less than that for the N1 site.

\section{Air Temparature Comparison}

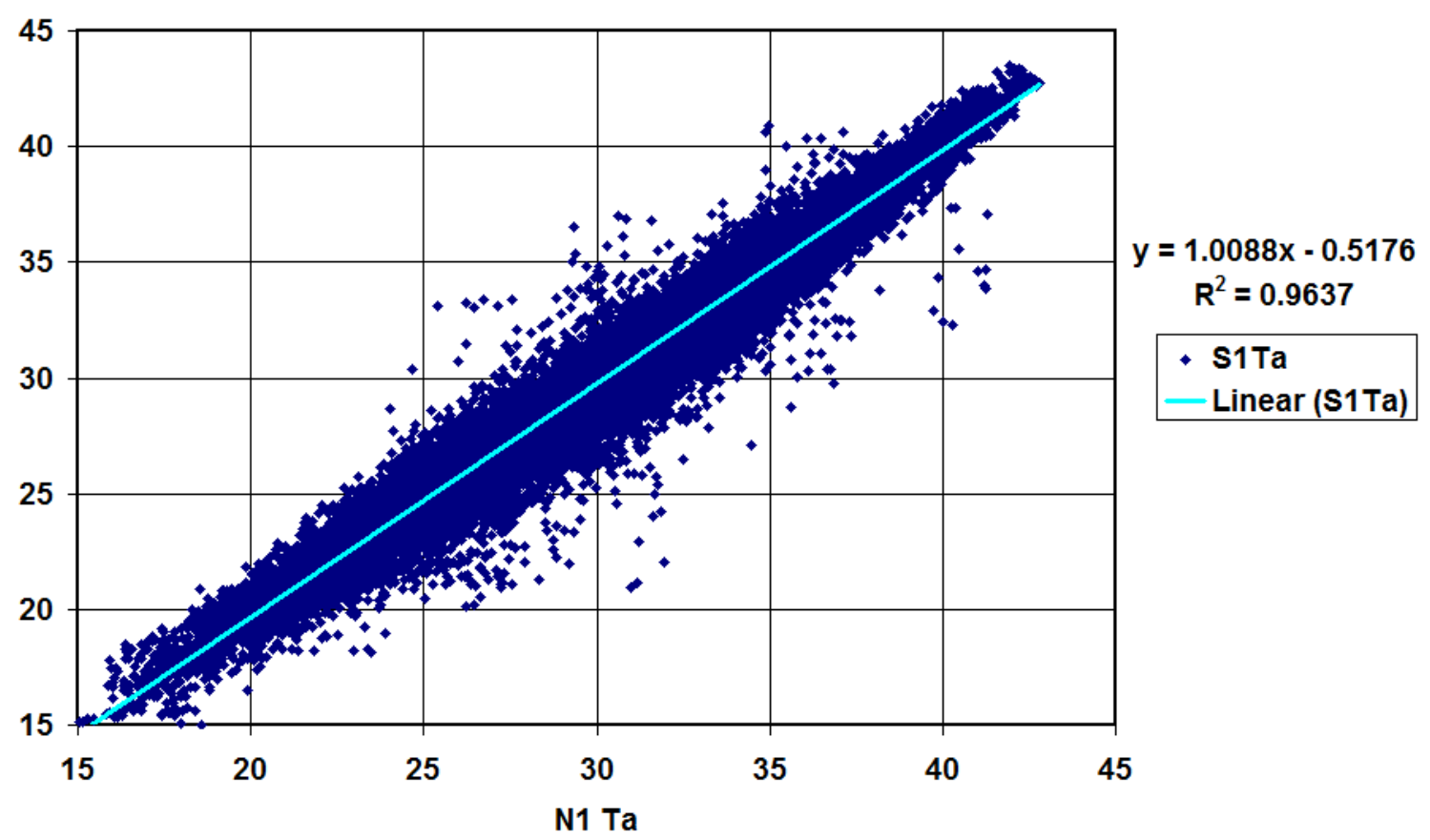

Figure 9. Comparison of $\mathrm{N} 1$ and $\mathrm{S} 1$ ambient air temperature (degrees $\mathrm{C}$ ). 
Vapor Pressure Comparison

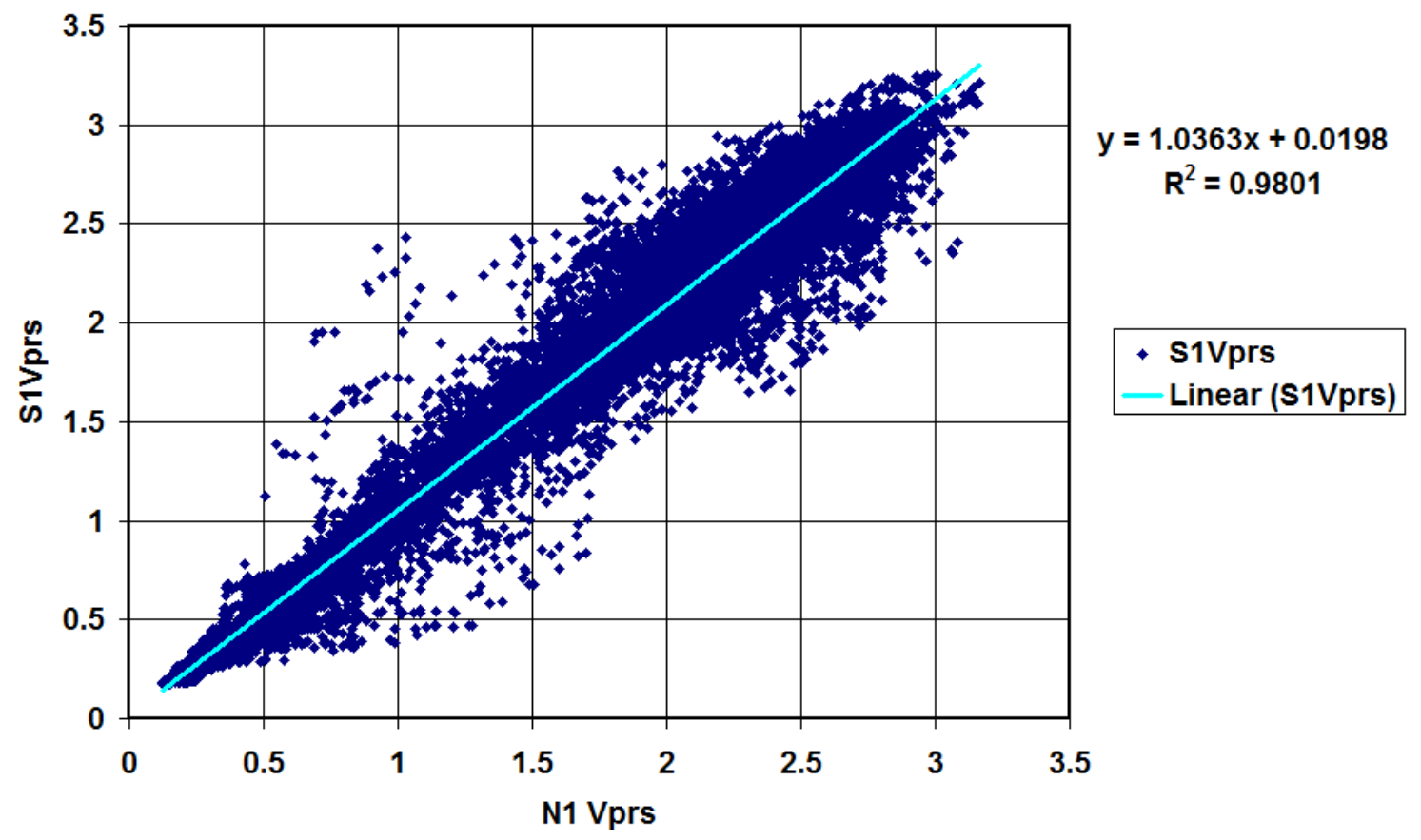

Figure 10. Comparison of $\mathrm{N} 1$ and $\mathrm{S} 1$ ambient vapor pressure ( $\mathrm{kPa})$.

Brutsaert Estimated Clear LWdn

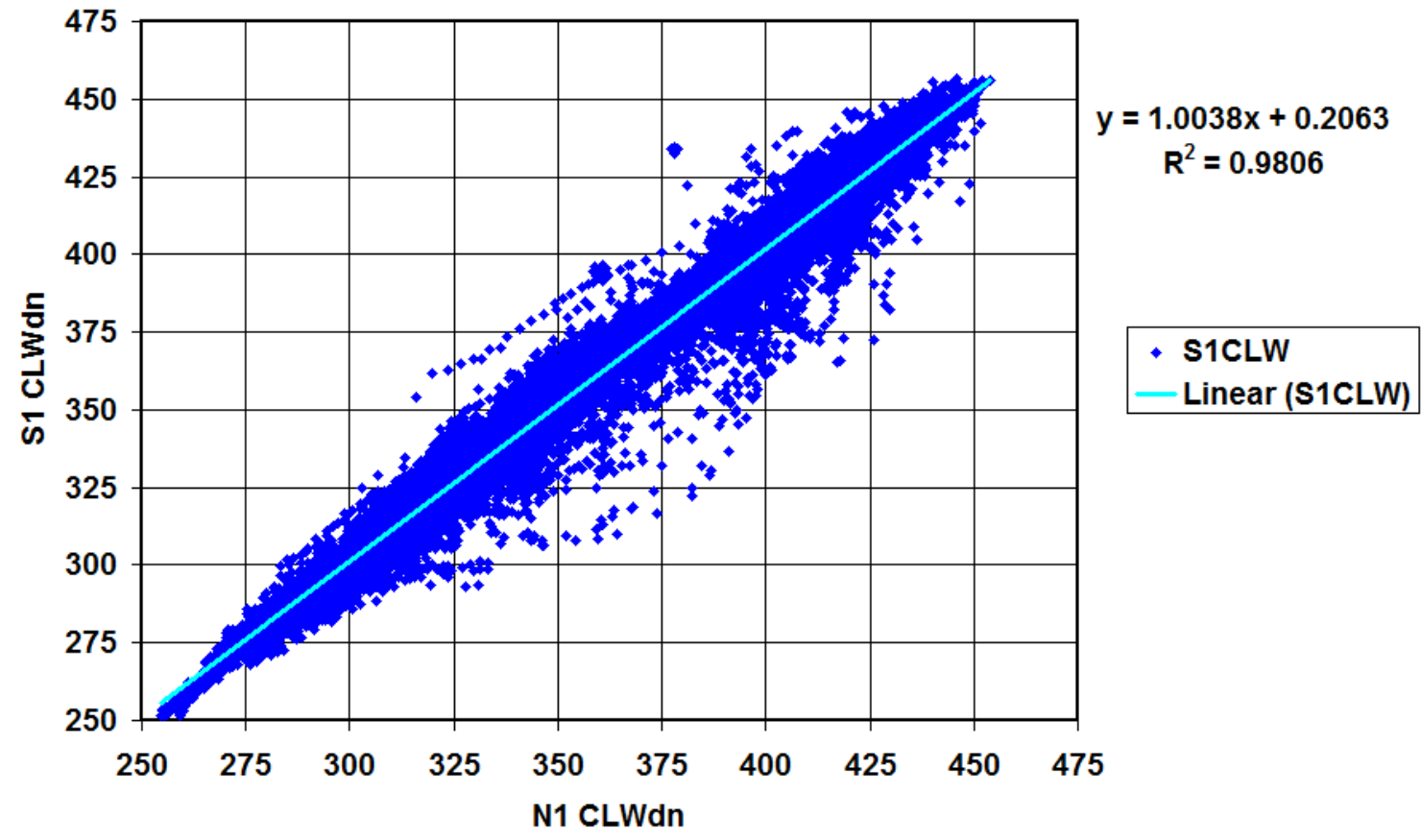

Figure 11. Comparison of $\mathrm{N} 1$ and $\mathrm{S} 1$ estimated clear-sky LWdn (Wm-2). 
Besides the atmospheric state, the LWdn is influenced by cloudiness and (especially for the Niamey deployment) significant low and mid-atmosphere aerosol loading. Unfortunately there were no instruments fielded at the S1 site that directly measures cloud amount, nor the vertical distribution of cloud and aerosol. However, the downwelling SW (SWdn) is significantly influenced by both. A comparison of SWdn between the two sites as measured by the unshaded PSPs (Figure 12) and a comparison of the relative frequency of occurrence of SWdn between the two sites (Figure 13) again exhibits no significant aggregate differences, suggesting that at least for the daylight periods there is no significant overarching differences in cloud and heavy aerosol occurrences between the two sites.

In the case of aerosols, each site fielded a Multi-filter Rotating Shadowband Radiometer (MFRSR) used to infer aerosol optical thickness (AOT) and have been processed by Dr. Jim Barnard. Table 1 shows the overall averages for the six spectral channels of the MFRSR, as well as the Angstrom coefficient. In all channels and for the Angstrom coefficient, the aggregate average and standard deviation differences amount to only few hundredths. Figure 14 shows the relative frequency of occurrence of the $500 \mathrm{~nm}$ AOT for the N1 and S1 sites. Again there are some small differences in the frequency distributions, with the N1 site having a bit less AOT occurrences at 0.2 AOT and about the same amount greater occurrences for 0.6 AOT. But both distributions show a strong peak for 0.4 AOT and the same decreasing occurrences for larger AOT. These small aggregate differences in overall average, standard deviation, and frequency of occurrence of AOT and SWdn do not suggest significant aggregate differences in cloud and aerosols between the two sites, at least for daylight times.

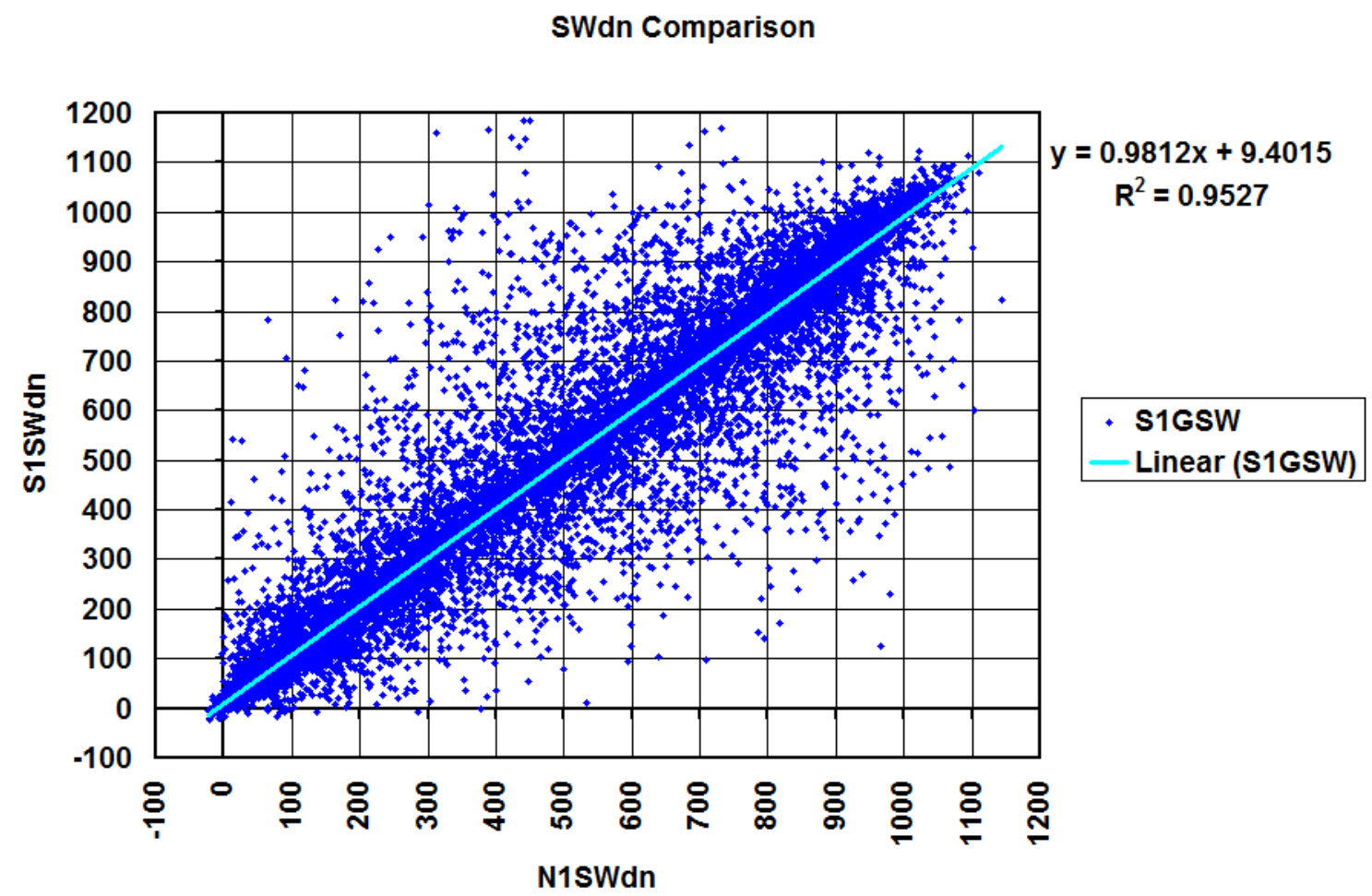

Figure 12. Comparison of $\mathrm{N} 1$ and $\mathrm{S} 1 \mathrm{SWdn}(\mathrm{Wm}-2)$. 


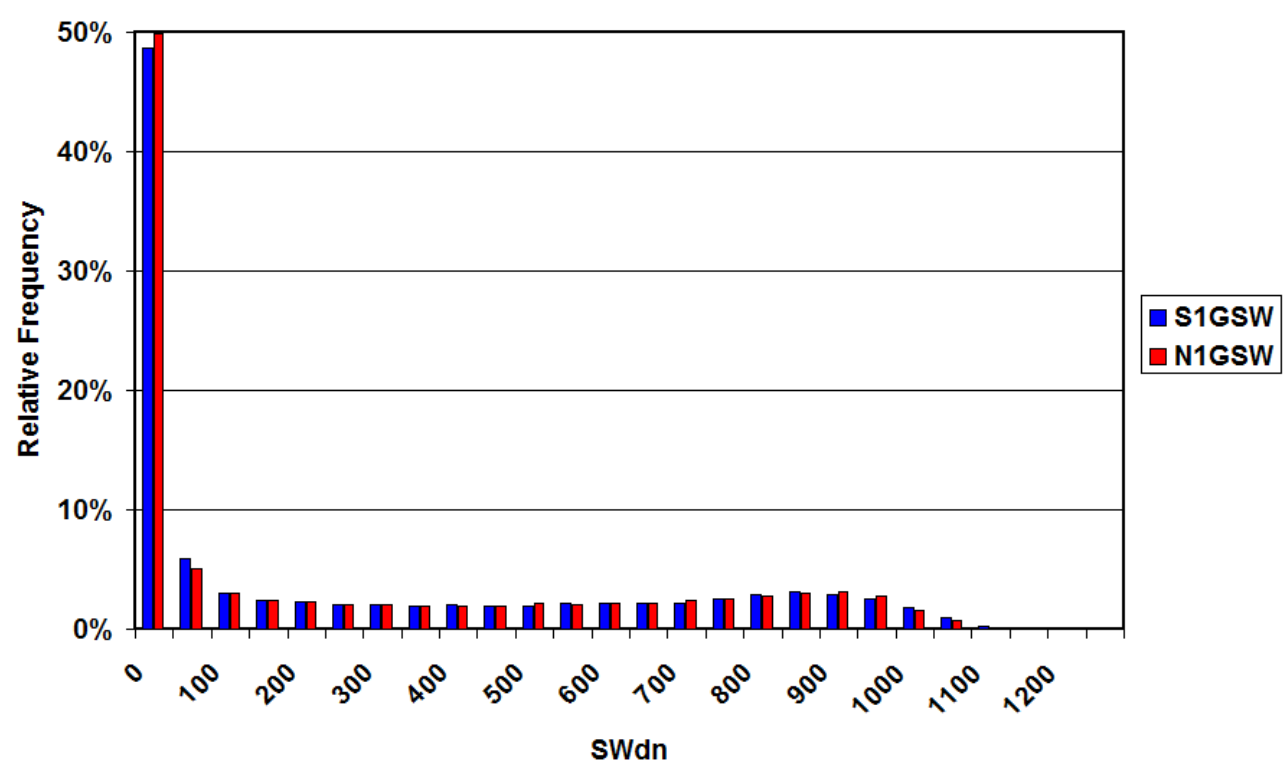

Figure 13. Relative frequency of occurrence for the N1 and S1 SWdn for the study period.

Table 1. N1 and S1 aggregate averages and standard deviations of MFRSR spectral aerosol optical thickness and Angstrom coefficient.

\begin{tabular}{|r|c|c|c|c|c|c|c|}
\hline & AOT_415 & AOT_500 & AOT_615 & AOT_673 & AOT_870 & AOT_940 & Angstrom \\
\hline S1Avg: & 0.7137 & 0.6921 & 0.6823 & 0.6794 & 0.6718 & 0.6681 & 0.2300 \\
\hline S1StDev: & 0.6446 & 0.6503 & 0.6621 & 0.6681 & 0.6729 & 0.6759 & 0.2515 \\
\hline N1Avg: & 0.7408 & 0.7056 & 0.6906 & 0.6822 & 0.6697 & 0.6633 & 0.2541 \\
\hline N1StDev: & 0.6189 & 0.6190 & 0.6249 & 0.6288 & 0.6334 & 0.6348 & 0.2022 \\
\hline
\end{tabular}

S1 and N1 Frequency of $500 \mathrm{~nm}$ AOT

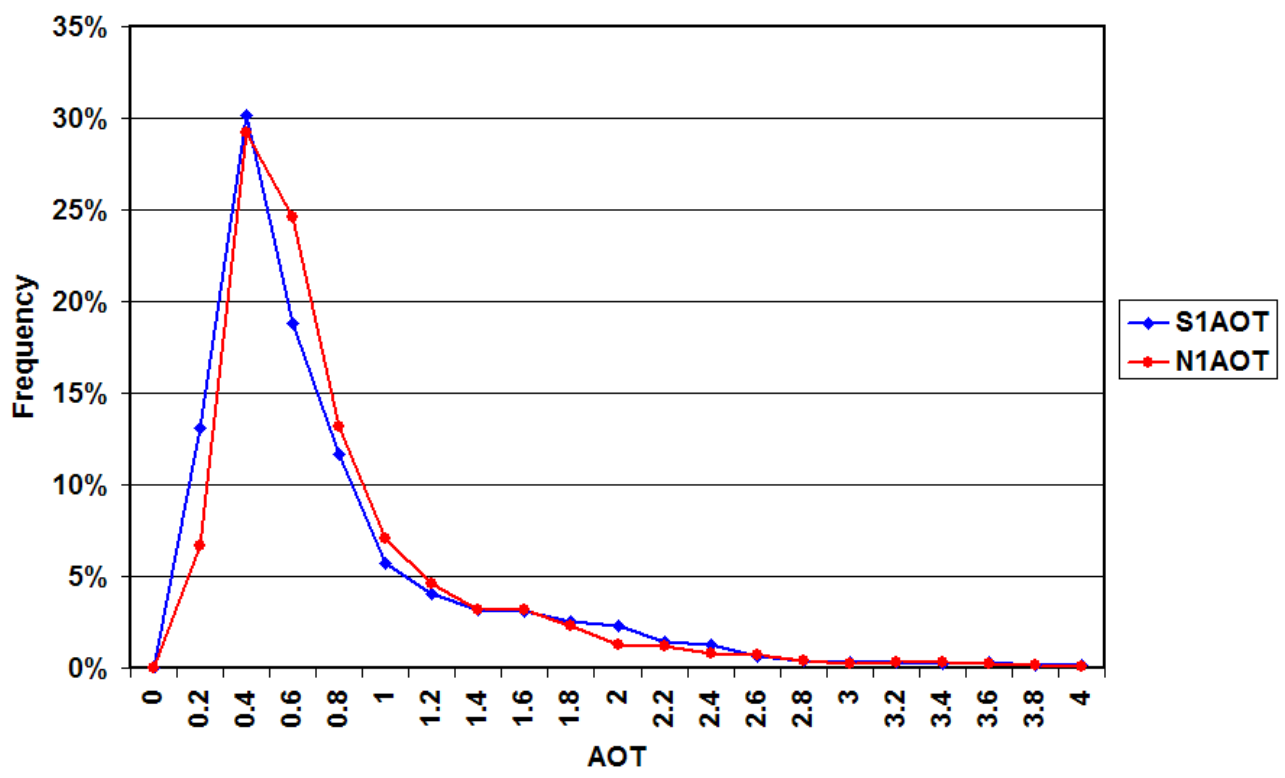

Figure 14. Relative frequency of occurrence for the N1 and S1 $500 \mathrm{~nm}$ aerosol optical thickness. 
To test whether perhaps significant differences might occur at night, we separate the LWdn data into "day" from 0600 - 1800 UTC, and "night" as the rest of the times. Figure 15 shows the comparison between the N1 \#1 LWdn to the S1 LWdn separated between "day" and "night” time periods as described. As can be seen, there is no significant aggregate difference in the day/night comparisons, as noted by the fitted lines. If there were significant differences in cloud/aerosol effects between the two sites at night compared to during the day, then there should be significant differences in the comparison in Figure 15. Since there are not, this result suggests that there are no significant cloud/aerosol influence differences between the two sites at night, either.

\section{Day and Night LWdn Comparison}

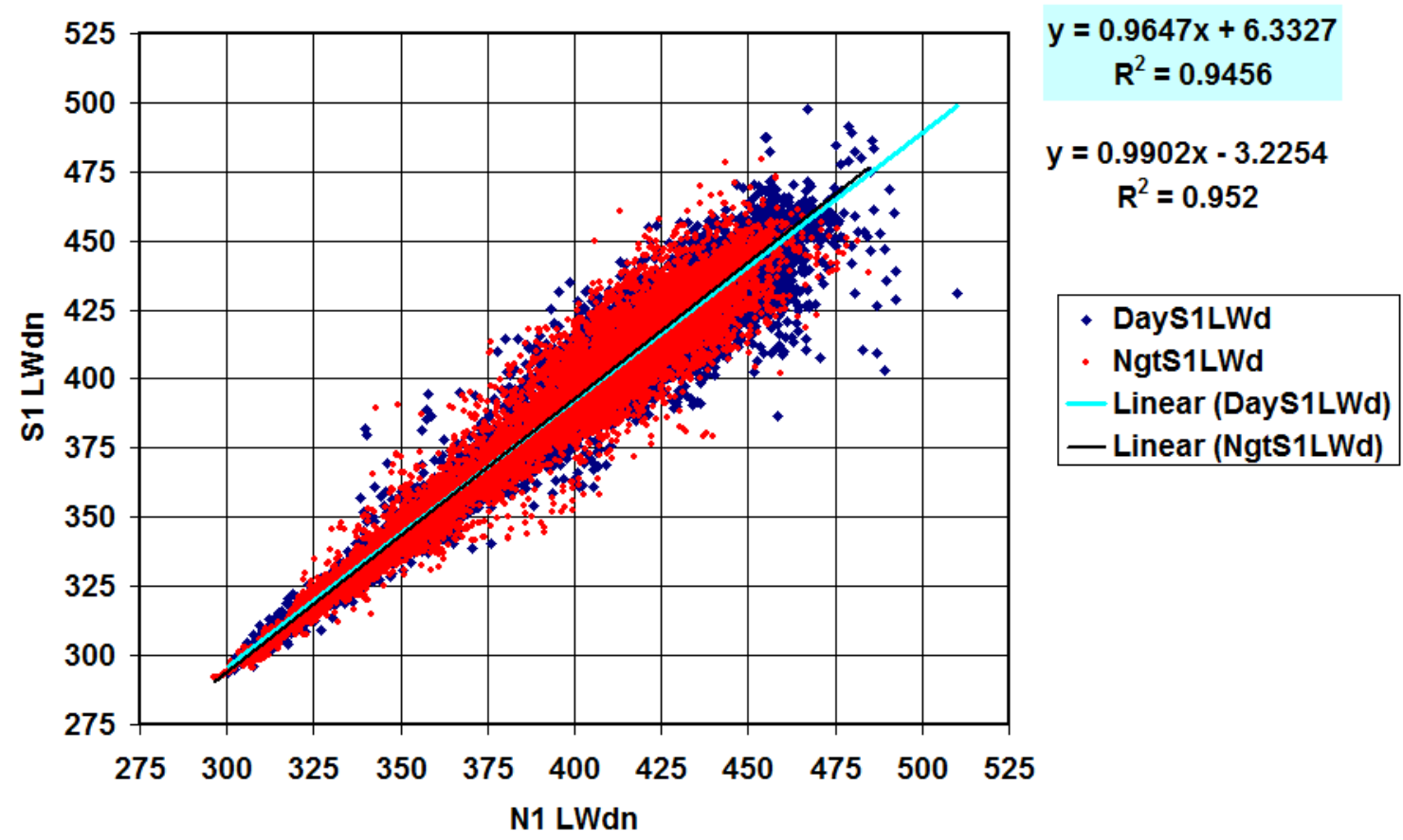

Figure 15. Comparison of $\mathrm{N} 1$ and S1 LWdn (Wm-2) separated between day (blue representing 06001800 UTC) and night (red representing all other times).

\section{Investigation of Cause of Differences}

If we rule out significant differences in atmospheric state and cloud/aerosol influences on LWdn between the two sites, then by default the differences must be caused by some instrument system differences. As shown previously (Figures 5 and 6), the case and dome temperatures of the S1 precision infrared radiometer (PIR) are significantly lower than those of the two N1 PIRs. Figure 16 shows the overall total averages and standard deviations of the air, case, and dome temperatures for the two sites. This plot reveals that the two N1 PIRs have about the same case temperatures (Tc), the same dome temperatures (Td), with about the same standard deviations for all four temperatures. The dome temperatures are slightly less than the corresponding case temperatures for both instruments. For the air temperatures (Ta), the average and standard deviations for the two sites are again about equal. The main differences are that the $\mathrm{S} 1 \mathrm{Tc}$ and $\mathrm{Td}$ are both about $3^{\circ} \mathrm{C}$ less than the corresponding $\mathrm{N} 1$ values with slightly larger standard deviations, and the S1 average Td is slightly greater than the S1 average Tc. 
Figure 17 shows a comparison of the PIR Tc and Td minus corresponding Ta, using the N1 \#1 instrument Tc-Ta difference as a comparator. The N1 \#1 Td-Ta difference is tightly correlated with the N1 \#1 Tc-Ta difference. The same is true for the N1 \#2 Tc-Ta and Td-Ta differences (not shown). However, Both the S1 Tc-Ta and Td-Ta differences do not exhibit nearly the same correlation. This shows that there is a significantly different relationship between the PIR case and dome and corresponding ambient air temperatures between the two sites. It is noted, though, that the S1 Tc-Ta and Td-Ta relationships are very similar to one another.

\section{Average and StDev of Temperatures}

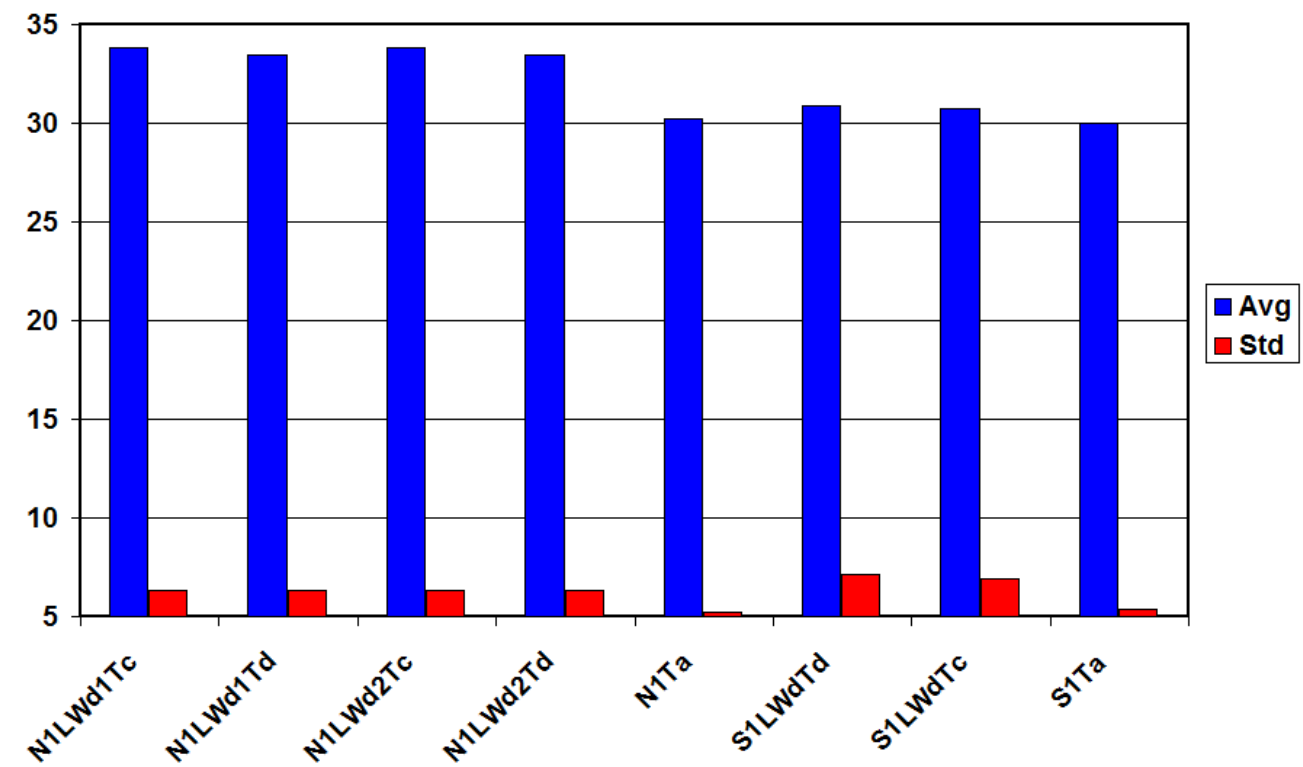

Figure 16. Aggregate average and standard deviations of the case, dome, and air temperature measurements for the $\mathrm{N} 1$ and $\mathrm{S} 1$ sites.

\section{Case and Dome Temperature minus Air Temperature}

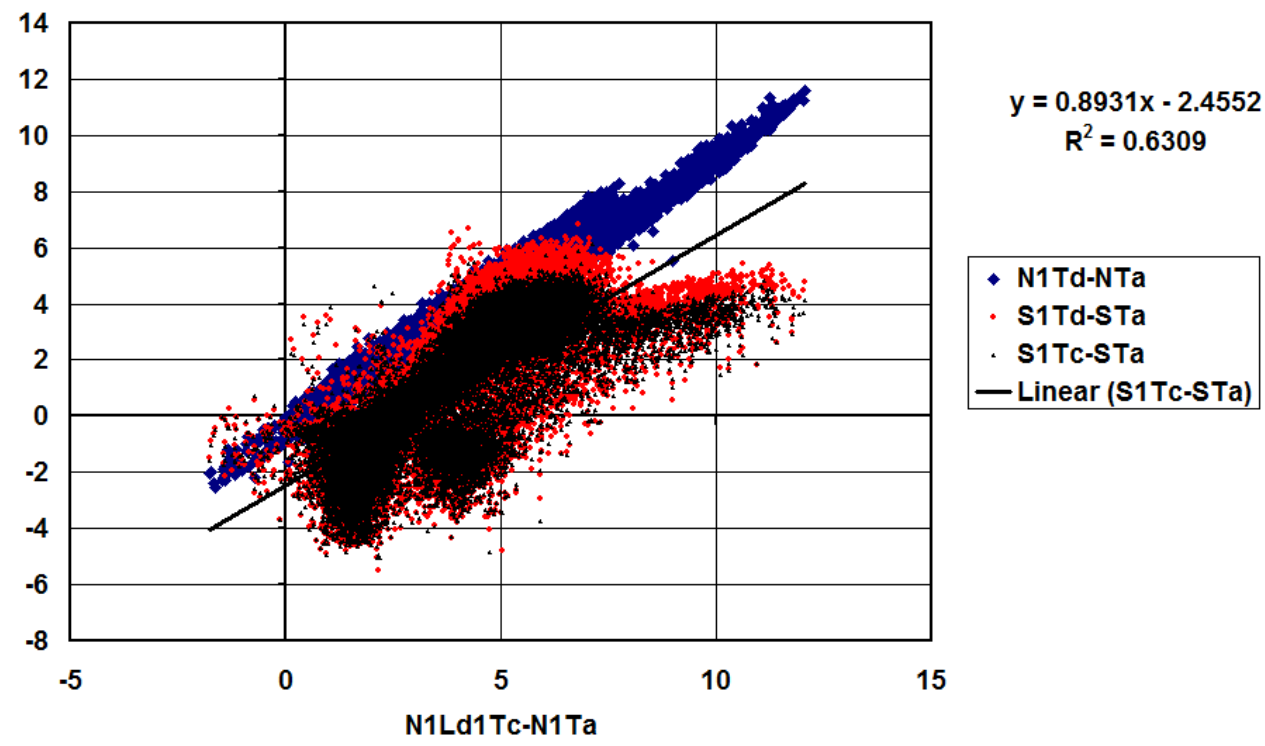

Figure 17. Comparison of PIR case and dome minus corresponding air temperatures for the N1 and S1 sites. 
Figure 18 shows the Tc-Td difference of each instrument versus corresponding air temperature. Both the $\mathrm{N} 1$ radiometers show the majority of the time that Tc is greater than Td (positive difference value), on average by about $0.5^{\circ} \mathrm{C}$. For the $\mathrm{S} 1$ instrument, though, a significant number of the data show $\mathrm{Td}>\mathrm{Tc}$ (a negative difference). However, it should be noted that while all three PIRs were ventilated, the S1 PIR was unshaded from direct sunlight whereas the two N1 PIRs were mounted on a solar tracker and shaded from direct sunlight. In the unshaded configuration, daylight exposure to the direct sun can heat the dome more than the case, the latter being protected from direct exposure by the instrument sun shield. Figure 19 shows the same plot as Figure 18, but with the light blue representing the S1 radiometer data for nighttime only. The nighttime data exhibit positive difference values, showing that all the negative difference values occur during daylight hours. Thus, an initial thought might be that perhaps the case and dome temperature channels were reversed on the S1 data logger. Figure 19, and a recomputation of the S1 LWdn from the case and dome temperatures (calculated from the resistances), and detector flux (calculated from the detector millivolt signals) compared to the original LWdn values included in the output files (not shown), shows that the case and dome temperatures are correctly labeled. It should also be noted that the formula used for calculating LWdn from the Tc, Td, and Detector flux components includes a term to account for the influence of the Tc-Td difference. Thus times with $\mathrm{Td}>\mathrm{Tc}$ should be accounted for in the calculation, just as times with $\mathrm{Td}<\mathrm{Tc}$ are.

The results in Figure 17 still pose a question of some possible problem, other than what appear to be anomalously low values, with the S1 Tc and Td values. To investigate this possibility, comparison of various permutations of SWdn and the various temperatures are studied. Figure 20 shows a comparison of the N1 and S1 air temperatures versus SWdn, which indicates no significant difference in the relationship between the two sites. Figure 21 shows the same comparison to SWdn, but for the three sets of Td values. Here all three Td sets show the same basic distribution pattern relationship to SWdn, with the S1 Td shifted toward lower values compared to the two N1 radiometers. Similar results (not shown) are obtained when comparing Tc values.

We next investigate the temperature differences versus SWdn. Figure 22 shows N1 Td-Ta and Tc-Td differences plotted again versus SWdn. Here we see that as the SWdn increases, there is a tendency for Td-Ta difference to also increase. But for the Tc-Td difference there is a decreasing tendency, albeit only a small one, with increasing SWdn. Figure 23 shows the same comparison as Figure 22, but for the S1 site. Here the same relationship is exhibited for the Td-Ta difference as for the N1 data. The Tc-Td difference again decreases with increasing SWdn, but at a greater rate than for N1. This is due to the S1 PIR being operated in unshaded mode as noted previously. 
Tc-Td vs Ta

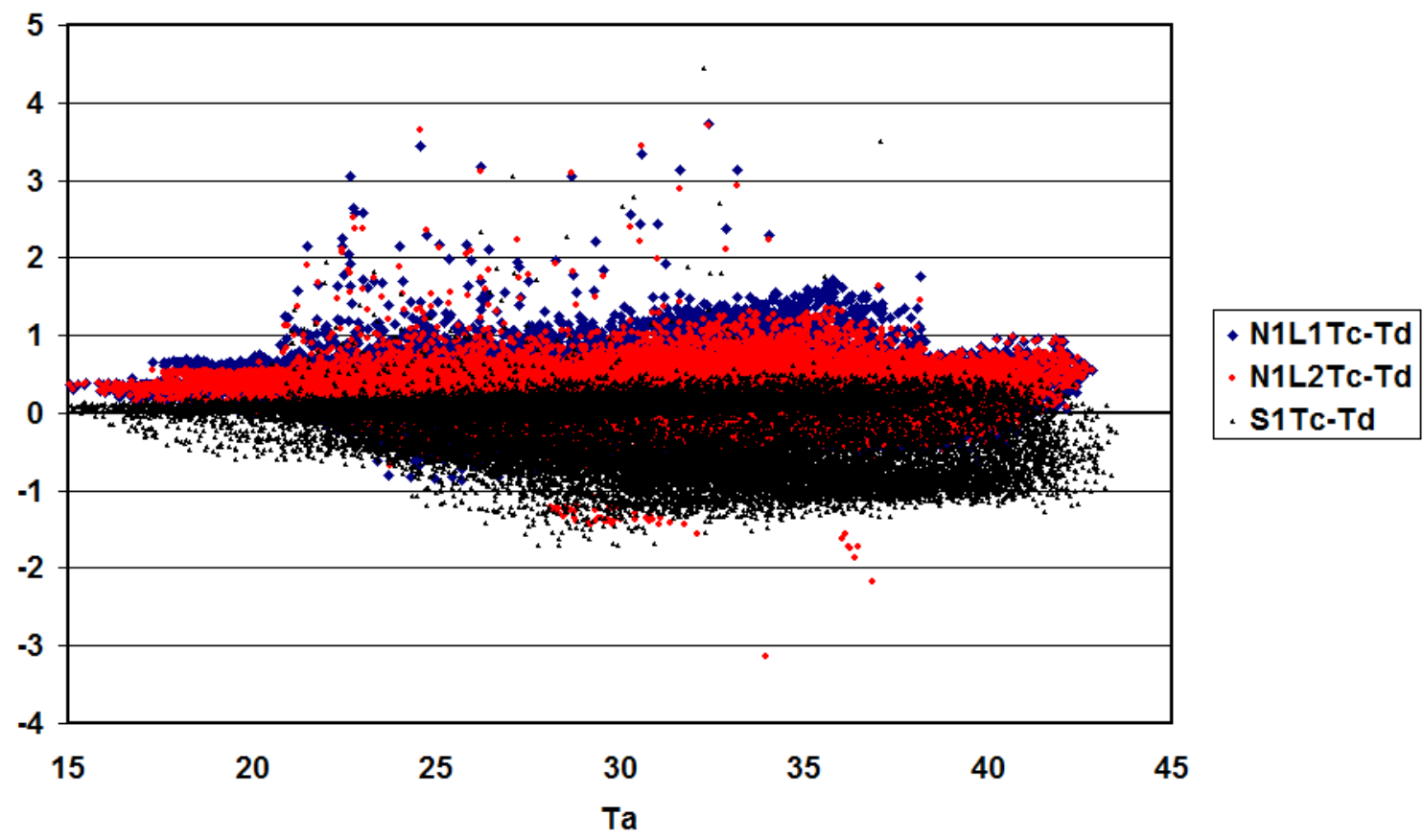

Figure 18. Comparison of PIR case minus dome temperature difference versus corresponding air temperatures for the N1 \#1 (blue) and \#2 (red) and S1 (black) sites.

\section{Tc-Td vs Ta}

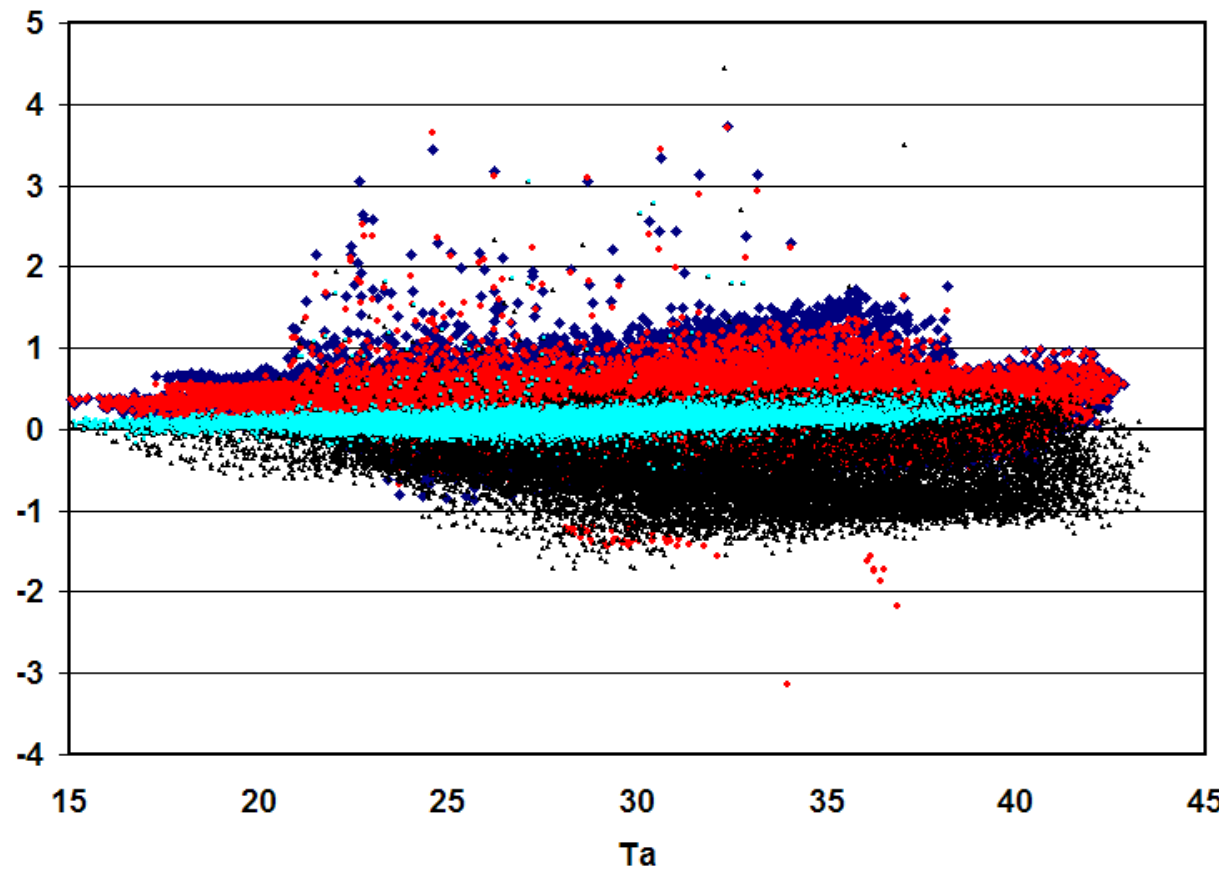

- N1L1TC-Td

N1L2TC-Td

S1Tc-Td

NgtS1Tc-Td

Figure 19. Same as Figure 18, but with the nighttime only S1 data (light blue) added. 
SWdn vs Air Temperature

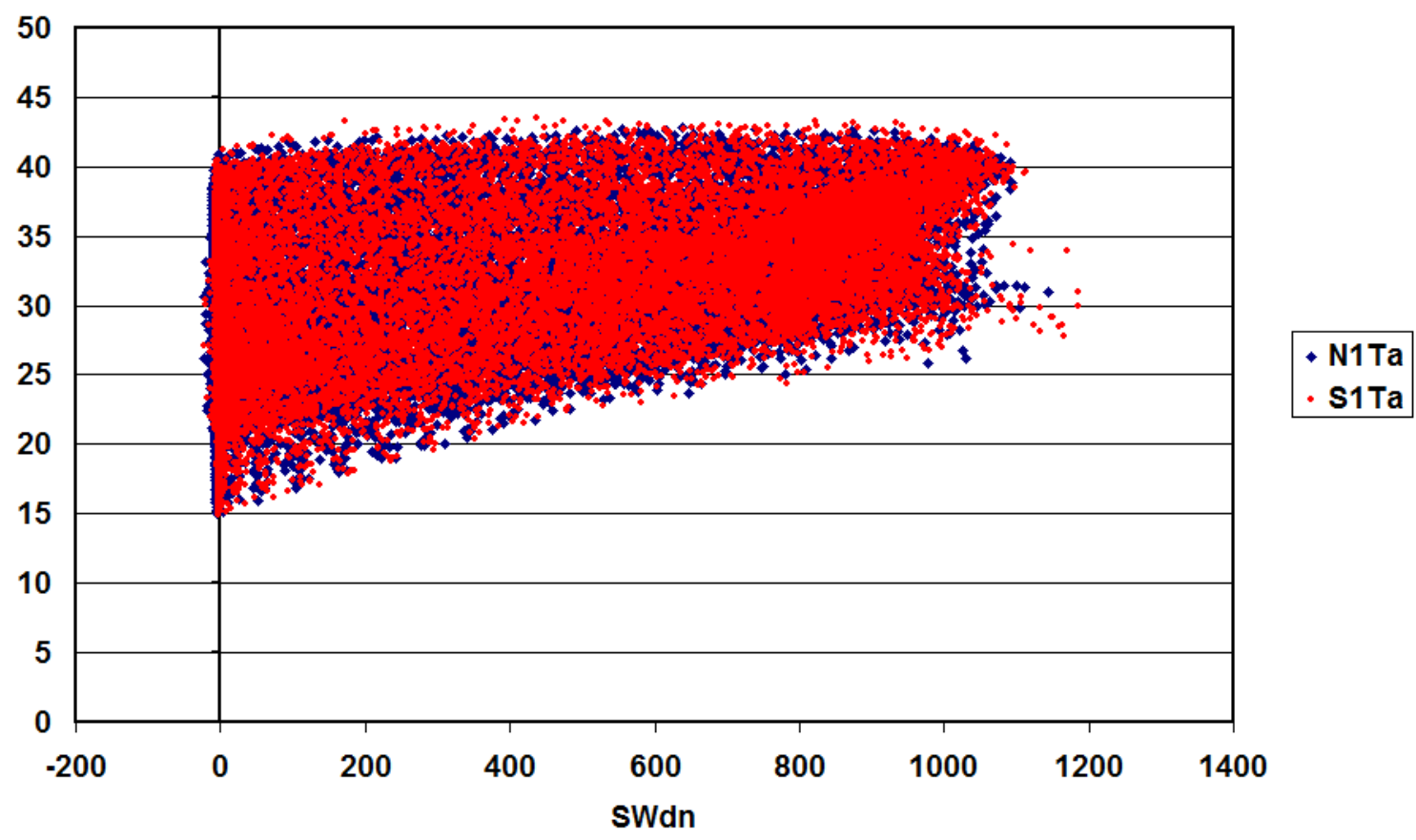

Figure 20. Comparison of $\mathrm{N} 1$ (blue, mostly hidden) and S1 (red) Ta to corresponding SWdn.

\section{SWdn vs Dome Temperature}

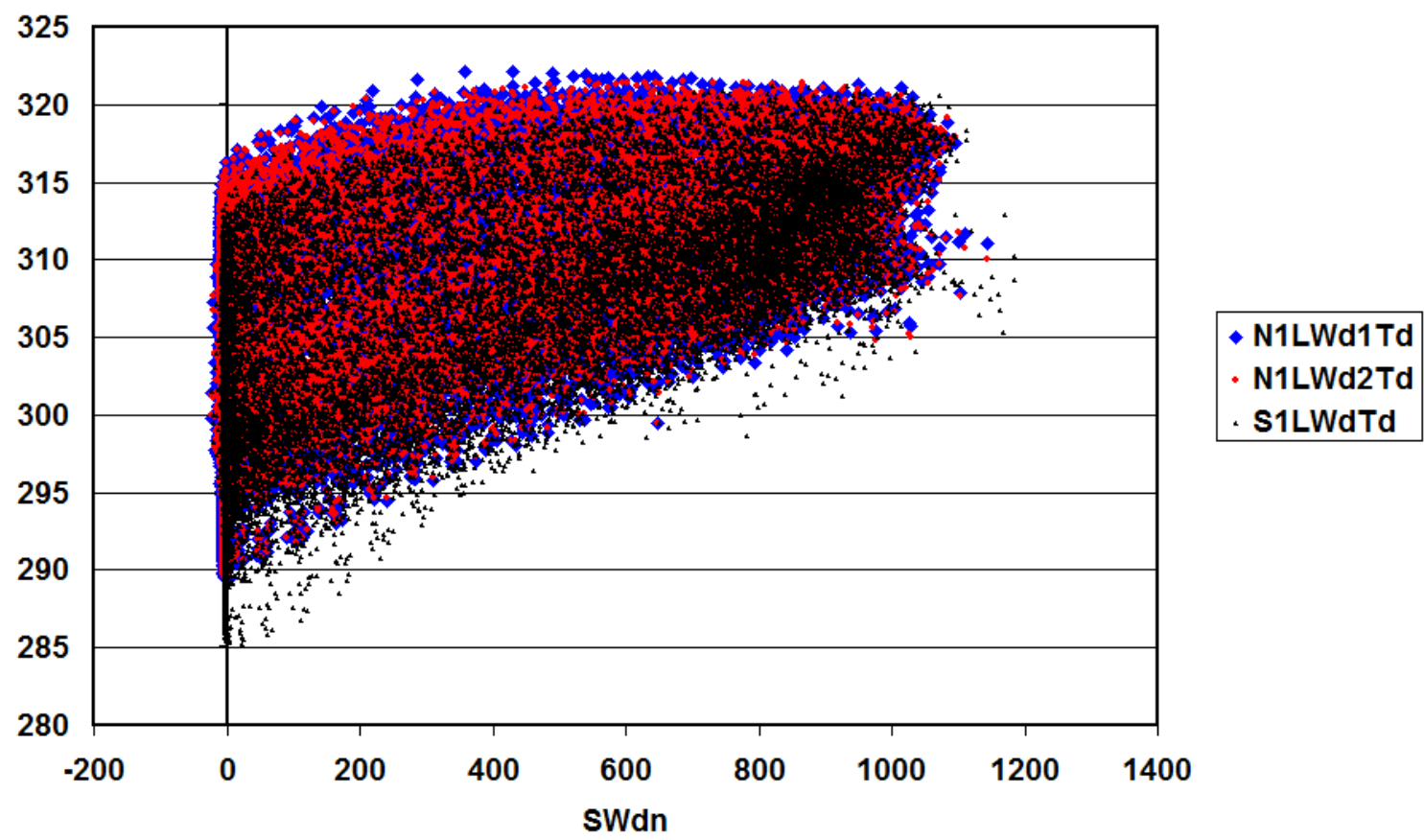

Figure 21. Comparison of $\mathrm{N} 1 \# 1$ (blue), \#2 (red) and S1 (black) Td to corresponding SWdn. 
N1 Temperature Differences vs SWdn

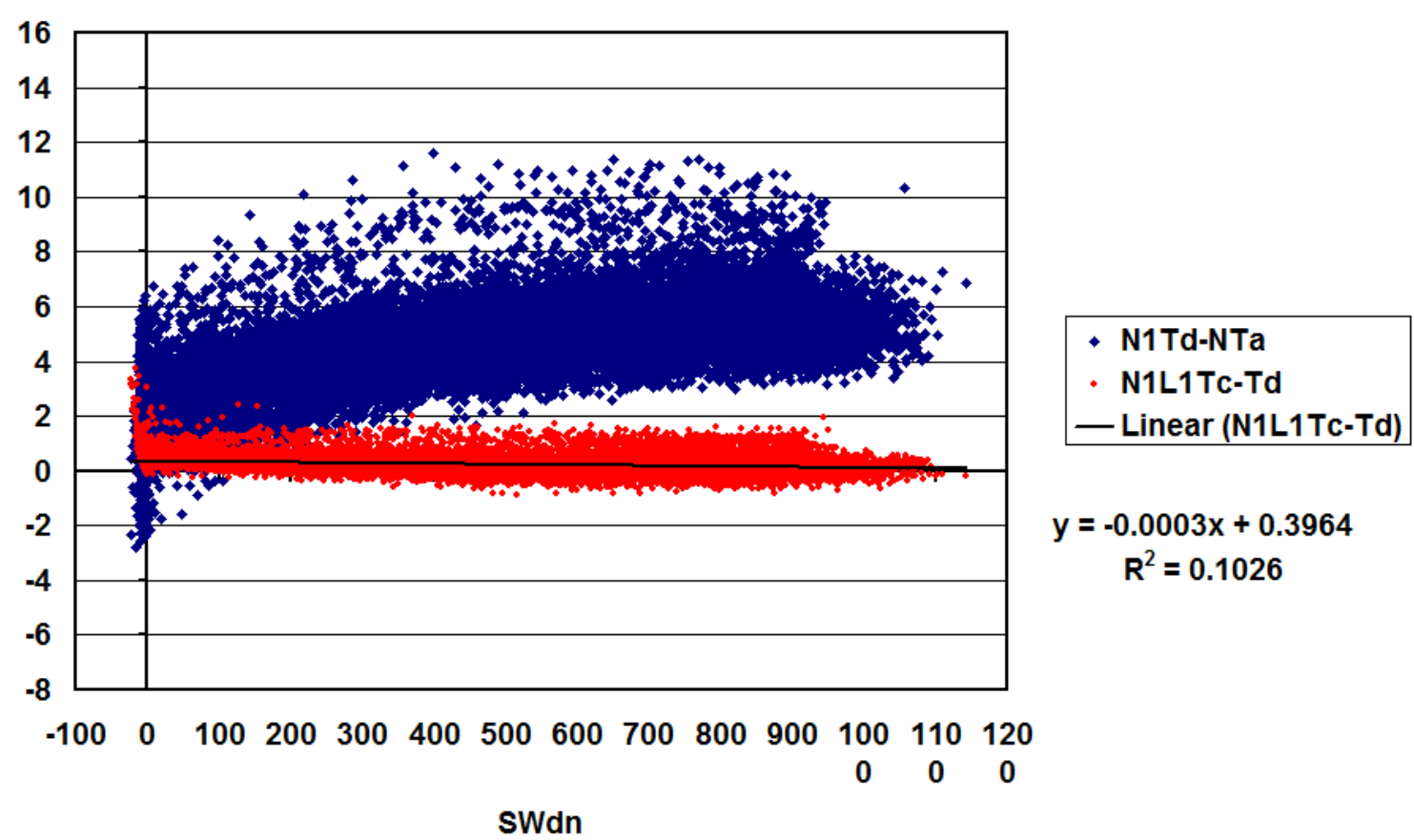

Figure 22. Td-Ta difference (blue) and Tc-Td difference (red) versus SWdn for the N1 site.

\$1 Temperature Differences vs SWdn

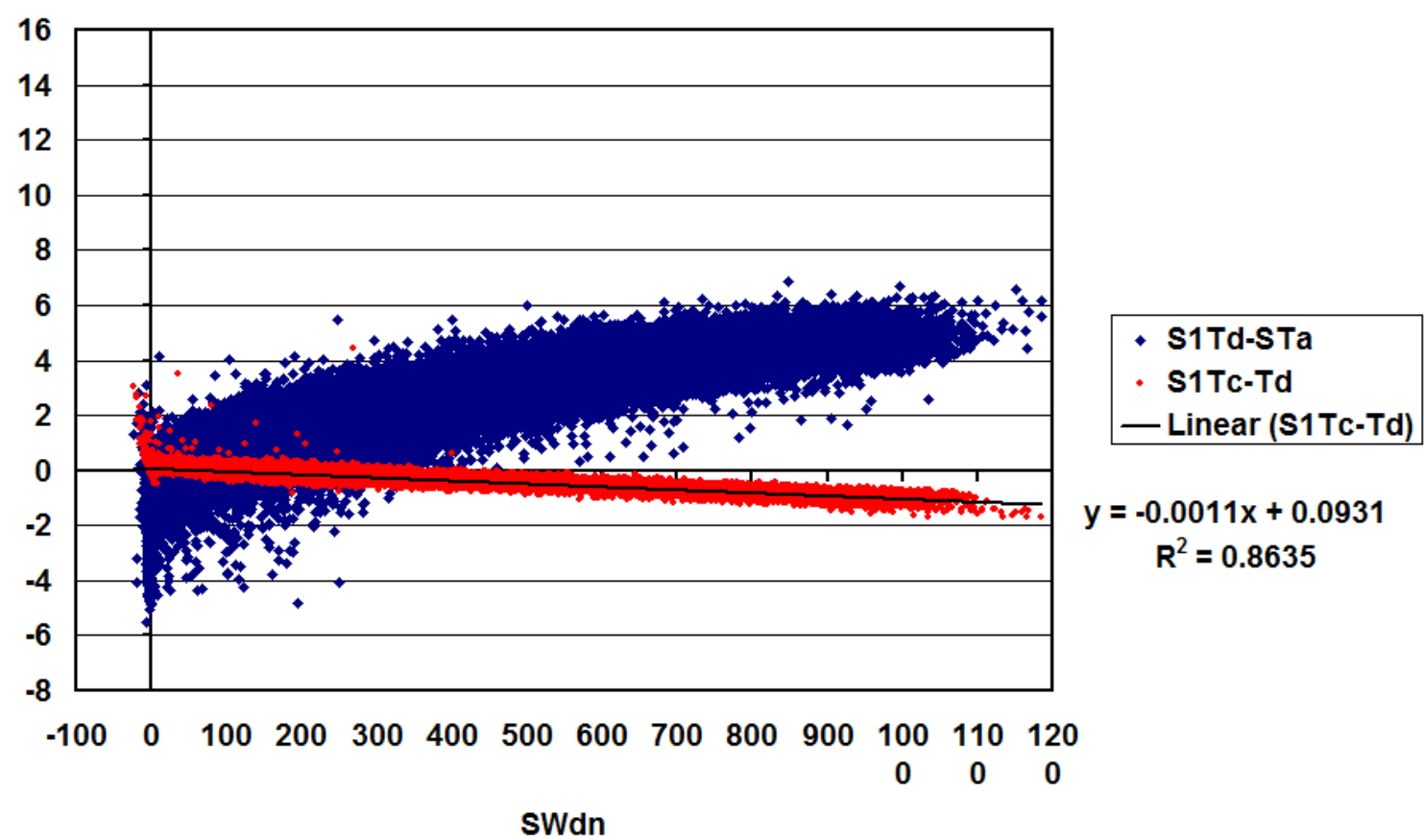

Figure 23. Same as Figure 19, but for the S1 site. 
The behavior shown in Figure 17 is perhaps explained by actual siting differences between the two sites. Figure 24 shows a picture of the N1 site, and Figure 25 a picture of the S1 site. Note that the ambient air temperature instrument at the N1 site (circled in red) is housed in an aspirated enclosure, and that enclosure is mounted at about the same height above ground as the ventilated radiometers on the sky stand (circled in blue). The S1 site layout (Figure 25), however, reveals that the ambient air temperature instrument is housed in a non-aspirated enclosure (red circle) and is mounted at a greater height above ground than the S1 ventilated downwelling radiometers (blue circle). These differences (aspirated versus non-aspirated but with both sets of radiometers ventilated, and relative height above ground differences) easily explain the differences in behavior shown in Figure 17 between the two sites. Thus, all the above analyses suggest that there is no anomalous behavior of the S1 case and dome temperatures other than their magnitude likely being too low.

\section{Summary and Recommendations}

As shown in Figure 16, in the aggregate average the $\mathrm{S} 1 \mathrm{Tc}$ and $\mathrm{Td}$ are about $3^{\circ} \mathrm{C}$ less than the corresponding $\mathrm{N} 1$ temperatures, with the associated S1 average LWdn about 7-8 $\mathrm{Wm}^{-2}$ less than the corresponding N1 measurements. All other analyses do not suggest any overall differences between the two sites that would indicate that the PIR case and dome temperatures and measured LWdn should differ to this extent. In fact, the analyses presented suggest quite the opposite.

It should be noted that the S1 data files included only the case and dome thermistor resistances, not the actual average temperatures themselves. The formula to convert the resistance to temperature is nonlinear, thus calculating the temperature from 15-minute average resistances gives a different value than a 15-minute average temperature from individual temperatures calculated from individual sample resistances. The same argument applies to using the case and dome temperatures to calculate the LW irradiance, another non-linear equation. How might this affect the results presented here? Figure 26 shows a comparison of the 15-minute average of the original N1 PIR \#1 values, which in turn are 1minute averages from 2-second sampling calculations, to the corresponding LWdn calculated using the 15-minute average case and dome temperatures. As can be seen, while there is scatter in the comparison producing an average absolute deviation of about $2 \mathrm{Wm}^{-2}$, in the aggregate there is no significant overall bias. Both sets of values produce the same overall average of $399.3 \mathrm{Wm}^{-2}$ with an $\mathrm{R}^{2}$ value of 0.992 and a slope of 0.97 for the linear fit. The $2 \mathrm{Wm}^{-2}$ average absolute deviation is consistent with results previously reported in Younkin and Long (2004). Despite the average absolute deviation, having no significant effect on the overall average and a slope of near unity can be translated to mean that there is no significant impact on the overarching results presented in this report.

There is substantial evidence that the mean downwelling LW differences over the period of deployment are greater than would be expected. Side-by-side comparisons of these instruments, but calibrated in a differently than by ARM currently, do consistently show closer agreement. Similarly, there is not any apparent physical environmental reason why a multi-month average between the two Niamey sites would be as large as reported. While the exact cause of the mean difference has not been specifically identified, there are only a few possibilities, barring some otherwise unexpected and undetected local mesoscale meteorological phenomenon. Those other possibilities are related to potential measurement error. We have shown comparisons of pyrgeometer and ambient air temperature measurements at the sites suggesting that, at the S1 site, the pyrgeometer temperatures were erroneously low. If those pyrgeometer temperatures were indeed too low, it would result in the derived downwelling $\mathrm{LW}$ results to be consistently too low. However, there has been no confirmation that the recorded pyrgeometer readings were actually in error. Other sources of measurement error that could contribute to the mean difference 
between the two sites have not been isolated, so it is not directly possible to determine how much the various sources of error could contribute to the observed difference. However, for various applications of the data and the remaining fact that there is no known reason for the sites to have different overarching downwelling LW climatologies, it appears reasonable to normalize the two data records. Our comparisons and analyses suggest that it would be most reasonable to make an adjustment to the S1 site's pyrgeometer temperatures as the normalization variable.

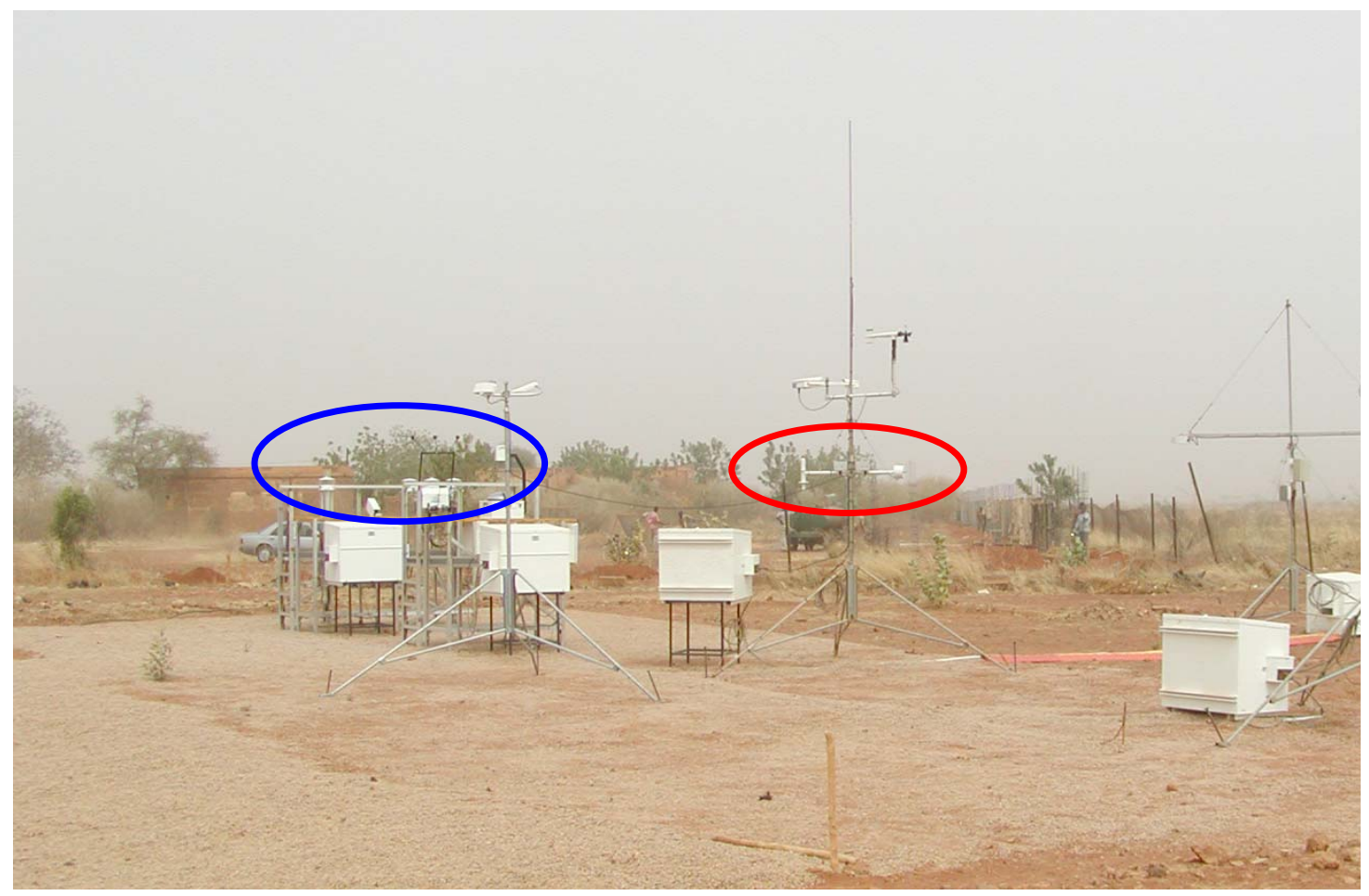

Figure 24. Picture of the N1 site radiometer and met instruments. Red circle is the ambient air temperature and moisture aspirated enclosure, blue circle is the downwelling radiometers.

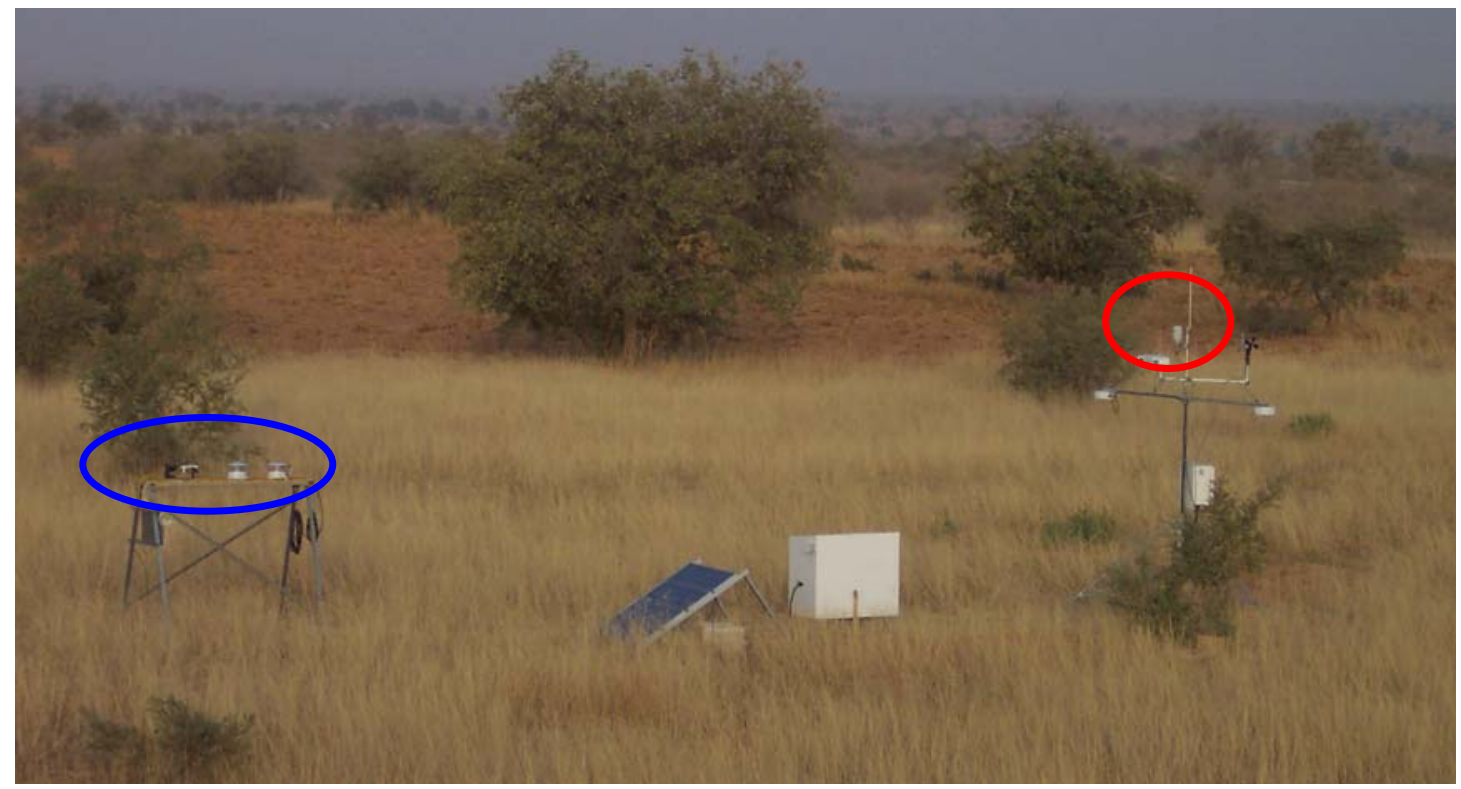

Figure 25. Picture of the S1 site radiometer and met instruments. Red circle is the ambient air temperature and moisture sun-shielded enclosure, blue circle is the downwelling radiometers. 
One might reasonably argue that, for some unknown reason, the S1 PIR case and dome temperatures as recorded were too low, and by a multiplicative factor, as suggested in Figures 5 and 6 . The two overall N1 LWdn averages (Figure 3) are $398.85 \mathrm{Wm}^{-2}$ and $398.12 \mathrm{Wm}^{-2}$, for the \#1 and \#2 instruments, respectively. Splitting the difference gives an average value of $398.5 \mathrm{Wm}^{-2}$ for the $\mathrm{N} 1$ site. Applying a multiplicative adjustment factor of 1.00305 to the S1 case and dome temperatures (in Kelvin), and then calculating the "adjusted LWdn," yields an overall average of $398.5 \mathrm{Wm}^{-2}$, which is equal to the N1 composite average (Figure 3, far right column). A comparison of this "normalized LWdn" (as well as the original S1 LWdn) to the N1 PIR\#1 LWdn is shown in Figure 27. The comparison for the "normalized LWdn” yields a linear slope of 0.999 with virtually no offset, and an $\mathrm{R}^{2}$ value of 0.95 .

Thus, our recommendation is that the S1 PIR case and dome temperatures, and LWdn, be reprocessed. The case and dome temperatures should be calculated from the stored thermistor resistances using the standard formula. The resultant temperatures (in Kelvin) should be multiplied by 1.00305, and then used to calculate the downwelling LW irradiance. These normalized values for the adjusted PIR case and dome temperatures and adjusted LWdn should then be used to replace the case and dome resistances, and LWdn values, currently in the S1 1-minute data files.

It is strongly recommended that future AMF deployments include side-by-side comparison with the main site instrumentation of the exact field configuration for the supplementary instrument systems, both before and after the deployment. It also is recommended that ARM discontinue its current pyrgeometer calibration dependence on decade-old original manufacturer calibration with fixed generic dome effect correction factors to one that consistently and accurately reproduces the developing international reference scale maintained in Davos, Switzerland.

\section{Comparison of Original and Calculated from 15-minute Data LWdn}

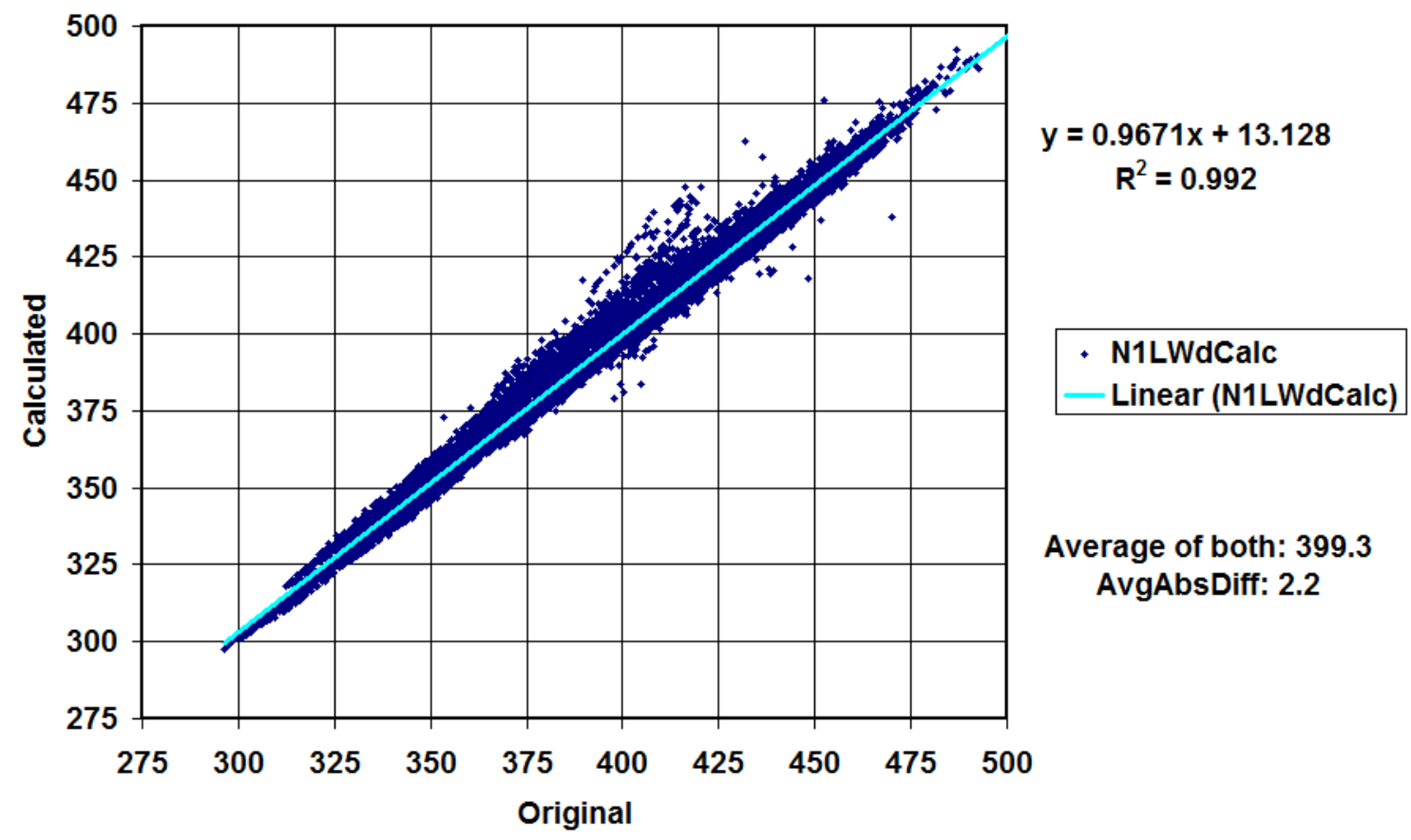

Figure 26. Comparison of 15-minute average of LWdn from 1-minute LWdn data versus LWdn calculated from 15-minute average case and dome temperatures for the N1 PIR\#1 instrument. 
Downwelling LW Comparison, Adjusted

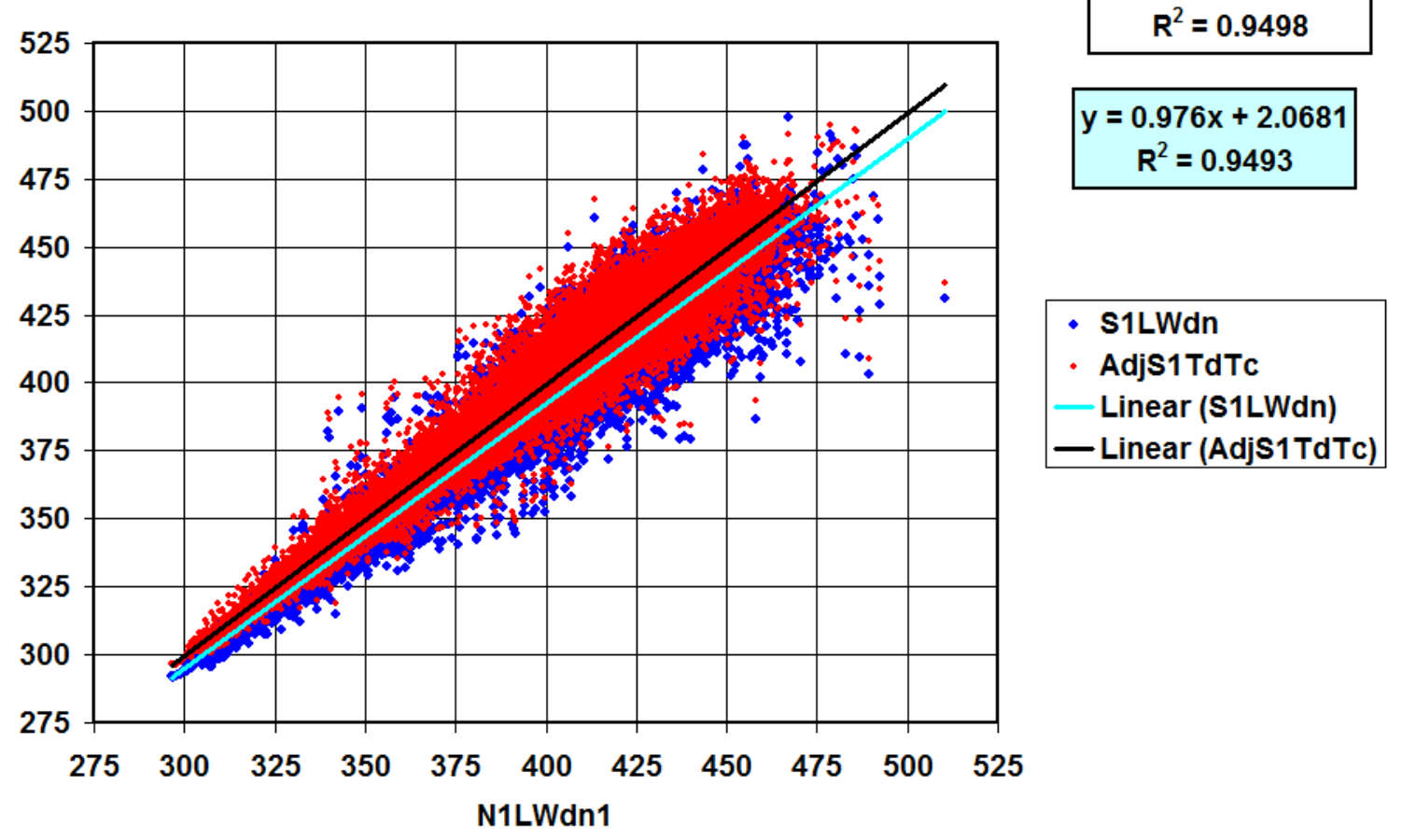

Figure 27. Comparison on original and "adjusted" S1 LWdn with the N1 PIR\#1 LWdn.

\section{Acknowledgment}

We gratefully acknowledge the support of the Climate Change Research Division of the U.S. Department of Energy as part of the Atmospheric Radiation Measurement (ARM) Program. We thank J. Michalsky, M.J. Bartholomew, and S. McFarlane for discussions and comments regarding this study; and J. Barnard for providing the aerosol optical thickness retrievals.

\section{References}

Brutsaert, W. 1975. “On a derivable formula for longwave radiation from clear skies.” Water Resour. Res. 11, $742-744$.

Ohmura, A. 2001. "Physical basis for the temperature-based melt-index method." J. Appl. Meteorol. 40, $753-761$.

Younkin, K, and CN Long. 2004. Improved Correction of IR Loss in Diffuse Shortwave Measurements: An ARM Value Added Product. U.S. Department of Energy. ARM/TR-009, 50 pp., Available via http://www.arm.gov. 